\title{
Rapid extraction of total lipids and lipophilic POPs from all EU-regulated foods of animal origin: Smedes' method revisited and enhanced
}

\author{
Johannes Haedrich ${ }^{1,3^{*}}$ (D) Claudia Stumpf ${ }^{1}$ and Michael S. Denison ${ }^{2}$
}

\begin{abstract}
Background: Persistent organic pollutants (POPs) such as dioxins, dioxin-like chemicals and non-dioxin-like PCBs causing adverse effects to human health bio-accumulate through the food web due to their affinity for adipose tissues. Foods of animal origin are therefore the main contributors to human dietary exposure. The European Union's (EU) food safety policy requires checking of a wide range of samples for compliance with legal limits on a regular basis. Several methods of varying efficiency are applied by official control laboratories for extraction of the different classes of lipids and associated POPs, bound to animal tissue and animal products in varying degrees, sometimes leading to discrepancies especially in fresh weight based analytical results.

Results: Starting from Smedes'lipid extraction from marine tissue, we optimized the extraction efficiency for both lipids and lipophilic pollutants, abandoning the time-consuming centrifugation step. The resulting modified Smedes extraction (MSE) method was validated based on multiple analyses of a large number of real-world samples, matrix calibration and performance assessment in proficiency testing utilizing both instrumental and bioanalytical methodologies. Intermediate precision in 12 different foods was below 3\% in chicken eggs, egg powder, animal fat, fish, fish oil, poultry, whole milk, milk fat and milk powder, and below $5 \%$ in bovine meat, liver, and infant food. In comparison to Twisselmann hot extraction, results presented here show an increased efficiency of MSE by $+25 \%$ for bovine liver, $+14 \%$ for chicken eggs, $+13 \%$ for poultry meat,$+12 \%$ for fish, $8 \%$ for bovine meat, and $6 \%$ for infant food.
\end{abstract}

Conclusions: For the first time, a fast and reliable routine method is available that enables the analyst to reproducibly extract "total" lipids from any EU-regulated food sample of animal origin within 6 to $8 \mathrm{~min}$. Increased efficiency translates into a considerable increase in both lipid and wet weight-based analytical results measured for associated POPs, reducing the risk of false non-compliant results. Compared to a $4 \mathrm{~h}$ Twisselmann extraction, the extraction of 1000 samples using MSE would result in annual savings of about $250 \mathrm{~h}$ or 32 working days. Our MSE procedure contributes to the European Commission's objective of harmonizing analytical results across the EU generated according to Commission Regulation (EU) 2017/644.

Keywords: Lipid extraction, Lipophilic POPs, Food of animal origin, EU legislation

*Correspondence: jfh3009@t-online.de

1 European Union Reference Laboratory (EU-RL) for Dioxins and PCBs in Feed and Food, CVUA Freiburg, Bissierstraße 5, 79114 Freiburg, Germany

Full list of author information is available at the end of the article

\section{Background}

Persistent organic pollutants (POPs) include a wide range of anthropogenic toxic compounds, including industrial chemicals such as pesticides (e.g. endrin, heptachlor, mirex, toxaphene), polychlorinated biphenyls (PCBs), hexachlorobenzene (HCB), brominated flame retardants, perfluorinated compounds, and by-products of industrial processes such as polychlorinated dibenzo- $p$-dioxins 
(PCDDs) and dibenzofurans (PCDFs). Because of chlorine, bromine, or fluoride groups on the hydrocarbon rings or chains, these chemicals persist both in the environment and in the human and animal body. They exponentially bio-accumulate through the food web due to their affinity for adipose tissues, posing a risk of causing adverse effects to human and animal health. For example, the main contributors to exposure, accounting for more than $90 \%$ of the current average dietary exposure of the European population to dioxins, dioxin-like chemicals (PCDFs and DL-PCBs) and non-dioxin-like PCBs (NDLPCBs), are milk, eggs, meat, fish, poultry and derived products, followed-due to high consumption-by the main group vegetables [1].

Due to their lipophilic nature, these POPs are usually found adhering to or dissolved in fatty tissue or milk fat. Therefore, methods of analysis for official control of the levels of lipophilic toxic compounds in EU-regulated foods of animal origin include an initial lipid extraction step, which isolates the lipids from potentially interfering compounds such as proteins, carbohydrates and other polar molecules. Especially in trace and ultra-trace analysis, lipid extraction requires proper validation towards its efficiency [2] in order not to significantly underestimate the level of contamination determined by the analytical procedure.

\section{Lipids in farmed animal tissues, eggs, milk and fish}

Lipids are a group of organic compounds with a considerable structural and functional diversity, often loosely defined as being hydrophobic or amphipathic (i.e. possessing both hydrophilic and lipophilic properties), and soluble in organic solvents. These physico-chemical features are present in a broad range of molecules such as fatty acids, phospholipids, glycolipids, sterols, sphingolipids, sulfolipids, amino lipids, steroids, terpenes and others [3]. Lipids are not found evenly distributed throughout the mammalian and nonmammalian (e.g. fish, bird, etc.) organism. Triacylglycerols and phospholipids featuring both polar and non-polar regions are common in mammalian cell membranes. Sphingomyelins, a type of sphingolipid, are important components of the membranes of nerve axons that promote nerve conduction [4]. Other fatty acids are stored as non-polar triacylglycerols and sterol esters in intracellular lipid droplets that function as long-term energy reservoirs and as a stockpile of fatty acids and sterols needed for membrane biosynthesis [5].

Tissue lipids may also be classified by the degree to which they are integrated into more complex lipids, or even tightly linked to proteins forming particular lipidprotein-complexes [6]. "Free" fatty acids with little or no binding include the fat of adipose tissue or distinct phospholipids functioning as important regulators of cell signalling. Lipids showing weak to moderately strong binding to other tissue components are found in myelin sheaths, blood cells (erythrocytes, eosinophils and neutrophils), mycobacteria, the isotropic disks of skeletal muscle, lipofuscins, and the cytoplasm of many cells. Structural lipids such as phospholipids, glycolipids and cholesterol are assembled in bilayer membranes and found covalently bound to proteins in cell nuclei, reticulin, and epithelial brush-borders, carrying out important functions in tissue metabolism and structure [7]

Adipose tissue is the main site for lipid storage and synthesis of fatty acids in mammals. Fat has been reported to comprise about $76 \%$ of wet adipose tissue from cattle and between 73 to $86 \%$ of wet adipose tissue from mature sheep [8]. As to its lipid composition, triacylglycerols are by far the major components of both bovine (81\%) and ovine (92\%) adipose tissue, accompanied by small amounts of mono- and diacylglycerols, cholesterol, free fatty acids and phospholipids which account for roughly $1 \%$ of lipids in bovine adipose tissue, and for $3 \%$ in that of sheep [8].

Lipids in the skeletal muscle of cattle are an integral part of the membranes, in adipocytes and as intracellular free lipid droplets. For example, intramuscular total lipids in the latissimus dorsi back muscle of 3-year-old cattle was determined to be $3.7 \%$ of wet tissue weight, while phospholipids were present at levels between 0.4 and $1.0 \%$; phospholipids were $1.2 \%$ of the wet weight of sheep back muscle [8]. Pig meat, however, is lean once the visible fat is removed, compared to bovine and sheep meats. Intramuscular lipids in pig back muscle were 1.3\% of wet tissue weight and comprised $67 \%$ triacylglycerols and $33 \%$ phospholipids, while the lipid content in chicken's back muscle was $1.0 \%$ and consisted of approximately equal amounts of triacylglycerols and phospholipids [9].

Liver of ruminant animals often contains lipids mainly as phospholipids and cholesterol in the tissue's membranous structures, and triacylglycerols as storage lipids. Lipid contents have been reported as $2.2 \%$ of calf liver wet weight ( $22 \%$ triacylglycerols, $4.6 \%$ mono- and diacylglycerols, $63 \%$ phospholipids), 3.3 to $6.2 \%$ of mature bovine liver wet weight ( $46 \%$ triacylglycerols, $49 \%$ phospholipids), and mature sheep liver contained $4.5 \%$ fat (49\% triacylglycerols, $10 \%$ free fatty acids, $34 \%$ phospholipids) [8]. Phosphatidylcholine and phosphatidylethanolamine were the main phospholipid components. Pikul et al. [10] found that chicken liver was $5.6 \%$ total lipids, which was composed of $51 \%$ triacylglycerols, $42 \%$ phospholipids, and $6 \%$ total cholesterol.

A large chicken egg of $60 \mathrm{~g}$ contains a total of $\sim 6 \mathrm{~g}$ of lipids, which are found almost exclusively in the egg yolk, a complex system containing a variety of particles 
suspended in a protein solution. Lipids make up one third of the yolk and consist of $62 \%$ triacylglycerols, $33 \%$ phospholipids (mainly phosphatidylcholine and phosphatidylethanolamine) and less than 5\% cholesterol [11]. Together with protein and free cholesterol, phospholipids surround micelle-like particles (lipoproteins) with a non-polar core of triacylglycerides and cholesterol esters [12].

Most of the lipids in cows milk exist as an oil-inwater emulsion of small globules from 0.1 to $20 \mu \mathrm{m}$ in diameter stabilized by the milk fat globule membrane (MFGM) enveloping each fat globule which prevents its enzymatic degradation by lipases. The MFGM is a phospholipid structure comprising a polar lipids bilayer, proteins, enzymes, neutral lipids and trace components, separating the triacylglycerol core of the fat droplet from the surrounding aqueous environment $[8$, 13]. However, this MFGM can be ruptured by external stresses (agitation, homogenization). Cow's milk contains a total of 3.3 to $4.7 \%$ lipids, which are composed of $96-98 \%$ triacylglycerols, $0.25-0.5 \%$ diacylglycerols, $0.2-1 \%$ phospholipids (about 30\% each of phosphatidylethanolamine, phosphatidylcholine, sphingomyelin [14]), $0.2-0.4 \%$ cholesterol and $0.1-0.4 \%$ free fatty acids $[8,15]$.

In fish tissue, the main lipid constituents are triacylglycerol and phosphoglycerides, both containing long chain fatty acids. Lean fish such as cod and haddock, which are active deep-water feeders, have their reserve lipids stored as triacylglycerols primarily in the liver $[14,16]$, while muscle mainly contains phospholipids. For example, haddock flesh contains a total of about $1 \%$ lipids, of which $0.1-0.2 \%$ are "free" lipids, the rest being "bound" to protein [6]. In contrast, fatty fish like herring, mackerel or rainbow trout are surface feeders with substantial amounts of lipids stored as triacylglycerols in the flesh [14, 16]. The CALIPSO study [17], conducted between 2003 and 2006 in four French coastal regions, showed that the fishes containing most total lipids were eel, salmon, swordfish and halibut, with respective average lipid levels of 20.4, 13.5, 12.4 and $11.7 \%$ wet weight (based on whole fish). Mackerel and sardine are also rich in lipids (7.1 and 5.7\% wet weight), while anglerfish, pout and cod display the lowest fat levels of 0.2 to $0.3 \%$ wet weight. In another study [18] including migratory, coastal and reef dwelling fishes from around Japan and the Northern Pacific region, total lipid contents in most muscle tissues were found to range from 0.9 to $7.4 \%$ wet weight, with a strongly varying proportion of phospholipids in the total muscular lipids between 9 and $81 \%$. However, with a range from 0.47 to $0.92 \%$ wet weight, the muscle phospholipid content showed a significantly smaller variation.

\section{Tissue distribution of lipophilic POPs}

Uptake of organic pollutants into the mammalian organism occurs by passive diffusion across the skin (e.g. from contaminated surfaces) the membranes lining the gut (contaminated food, or water) and lungs (contaminated vapour, droplets, or particles). Lipophilic organic molecules are absorbed from the gut often in association with fat, passing through the membrane barriers due to their affinity for the lipophilic properties of the membranes themselves. Subsequently, they are transported to the liver by the hepatic portal system [19]. Following absorption via lungs or skin, lipophilic POPs associated with lipoproteins and membranes of the blood cells will first travel to tissues other than the liver, resulting in a different initial pattern of distribution. Organic pollutants will be distributed within blood and lymph among various tissue compartments and eventually be stored in lipophilic environments such as fat depots, lipoproteins and cell membranes. Interestingly, Yu et al. [20] found inconsistent distributions of $10 \mathrm{PCB}$ congeners and 22 chlorinated pesticides in various lipid compartments in humans. They concluded that lipophilic xenobiotic levels in serum or even subcutaneous fat are not necessarily indicative of concentrations and patterns in other kinds of adipose tissue such as visceral, retroperitoneal, and pelvic fat. To some degree, lipid composition of the various adipose tissues may be reflected in different solubility of individual POPs in different depots in the same individual. Thus, the common assumption that POP serum concentrations and patterns are indicative of those in adipose tissues throughout the body is questionable [20].

Based on their solubility, lipophilic properties, and the enthalpic and entropic forces that govern ligand affinity and selectivity, organic pollutants associate with the different lipid classes present within each tissue. Some lipophilic pollutants incorporate even spontaneously into lipoproteins, their oily core providing an ideal domain. POPs have the potential for long-term disruption of metabolic and endocrine processes, and they may alter systemic metabolic, endocrine, and immune system functions. With the exception of the liver, stored lipophilic pollutants be subjected to metabolism only to a limited extent [19]. Over time, however, accumulated POPs are slowly released into the bloodstream, and more so during weight loss. In female mammals, lipophilic pollutants are secreted into the mammalian milk and may cross the placenta into a developing embryo. In chicken, lipophilic POPs are transported together with lipids into the egg and subsequently into the developing embryo [19].

In farmed animals including poultry, liver and adipose tissue are the major storage organs for POPs such as hexachlorocyclohexane $(\mathrm{HCH})$ isomers, $\mathrm{HCB}$, dioxins and $\mathrm{PCBs}$, and dichlorodiphenyltrichloroethane (DDT) 
and its principal metabolites [dichlorodiphenyldichloroethane (DDD) and dichlorodiphenyldichloroethylene (DDE)]. Hepatic sequestration may result in relatively high lipid-based concentrations compared to adipose tissue or meat [21-26]. Species-, chemical- and congenerspecific differences in the accumulation in liver lead to differences between the relative chemical and/or congener composition in liver and body fat [26]. Shen et al. [27] found, for instance, that in pigs, liver has a much higher potential to accumulate PCDD/Fs and dioxin-like chemicals (e.g. PCB 126) than lung, kidney, subcutaneous fat, mesentery and muscle. On the other hand, they found that liver did not specifically concentrate polybrominated diphenyl ether congeners as compared to the other tissues examined. Jandacek et al. [28] demonstrated that weight loss redistributed HCB from adipose tissue to brain and kidneys, while HCB in the liver increased after weight regain. These findings suggest that changes in weight affect the concentration of POPs in adipose tissue and critical organs [29]. Further studies investigating transfer and resulting tissue levels of dioxins and PCBs in cattle, sheep, goats, pigs and poultry, reported high ratios of lipid-based levels for liver to adipose tissue demonstrated hepatic sequestration and have been recognized by the EFSA Panel on Contaminants in the Food Chain (CONTAM) [26].

Fish are directly exposed to pollutants dissolved or suspended in water. Therefore, the uptake via the respiratory organs and the skin as well as ingestion of contaminated food, particles and sediments is equally important [19]. Distributions of POPs in fish meat and liver tissue correlate with lipid content and metabolic activity [30]. For example, lean fish with less than 5\% lipids, such as cod and seabream, accumulate higher concentrations of PCDD/Fs and DL-PCBs in their liver, while oily or fatty fish such as salmon and trout store these POPs to a greater extent in muscle [26]. In addition to lipid content, lipid composition seems to have a significant effect on the storage and bioaccumulation potential in fish. Neutral storage lipids are most important for the bioaccumulation of nonpolar residues (e.g. $\mathrm{HCH}$ ), while slightly polar pollutants are mainly stored in membrane lipids mainly consisting of polar glycerolipids [31]. PCBs were detected in both the membrane-bound and the "free" lipid fraction in fish [32, 33]. In fact, significant interspecies as well as tissue-specific differences in the lipid-based levels of NDL-PCBs (congeners most prevalent in technical mixtures) in fish have reported described by Brázová et al. [34]. Total PCB concentrations corresponded to the trophic position of individual fish species within the food chain and were found to be highest in liver, followed by adipose tissue $>$ muscles $>$ hard roe $>$ bones $>$ brain . Again, individual congeners were not distributed homogeneously within liver and adipose tissue, leading to differences in their relative composition [34]. These findings were confirmed by Kampire et al. [35] based on analysis of 236 organ samples of fish from the North End Lake in Port Elizabeth, South Africa, for lipid-based levels of 6 NDL-PCB congeners (PCB 28, 52, 101, 138, 153 and 180) and levels were the highest in liver, followed by gonads $>$ gills $>$ muscle. PCBs 153 and 138 showed higher concentrations than other congeners in all samples.

\section{Lipid extraction methods}

In principle, "free lipids" can be extracted relatively easily using solvents in which they are normally readily soluble without being denatured, such as, for example, hexane, toluene, cyclohexane and ethyl ether, and moderately polar solvents such as diethyl ether and chloroform. Unless solubilized by the presence of other lipids, polar lipids are removed only after treatment with a polar solvent such as methanol, ethanol or propan-2-ol. The latter solvent may also pick up a considerable portion of "bound lipids" which originally are tightly linked to proteins forming particular lipid-protein-complexes where van der Waals forces, hydrogen bonds and ionic bonds are involved [36].

Phospholipids of cell membranes are arranged in a lipid bilayer with their polar hydrophilic phosphate heads directed outwards and non-polar hydrophobic tails inwards. They require solvents of similar characteristics to perturb both the hydrophilic and non-polar interactions simultaneously. For this purpose, a combination of a non-polar and a polar solvent should be chosen. The former should make the mixture non-polar enough for interacting with the hydrophobic tails and extracting non-polar fats, while the latter makes it polar enough to interact with the hydrophilic regions, disturbing and eventually destroying the highly organized structure of the cell membrane. Using the non-polar solvent component in some excess will always maintain enough of the mixture's non-polar characteristic to extract fat properly. For extracting "trapped lipids" (e.g. in protein aggregates of cell membranes), the sample should be ground prior to the extraction procedure in order to break up the cell membranes and other structures that would make extraction difficult [37].

Numerous techniques for lipid extraction from samples of animal origin (e.g. fish, mammalian tissues, eggs) have evolved during the past 70 years $[6,38]$. These methods vary considerably with tissue properties, binding modes of target lipids and the information required from the sample (e.g. lipid composition, residues of lipidassociated POPs, analytical results based on fat or on wet weight). Diethyl ether, petrol ether, chloroform, methanol, ethanol, and various mixtures thereof were used as 
lipid extractants mainly from fish tissue during the early 1950s [6]. Several decades later, increasing awareness of the potential toxicity of solvents to analysts became another driving factor that facilitated change in solvent usage [36].

In 1957, Folch, Lees and Stanley [39] published their much-noticed paper on fat extraction from liver, muscle and brain tissue. In brief, samples are homogenized for several minutes with water and chloroform-methanol $(2: 1, \mathrm{v} / \mathrm{v})$ using a Potter-Elvehjem homogenizer for sample amounts up to $1 \mathrm{~g}$ and a blender for larger amounts. The ability of chloroform to associate with water molecules, probably by weak hydrogen bonds, is a key property making chloroform-methanol such a good lipid solvent [40]. More recently, Castro-Gómez et al. [41] used what became known as the classic "Folch-method" for extraction of total fat from raw whole milk from cows, sheep, and goats. However, it was the least efficient among several other procedures tested providing total milk fat yields of $47 \%, 84 \%$ and $77 \%$, respectively.

Bligh and Dyer [42] developed the "Folch-method" further in 1959, into a 3-step extraction of large amounts of wet tissue, especially frozen fish: (1) methanol-chloroform $(2: 1, \mathrm{v} / \mathrm{v}),(2)$ chloroform and (3) water are added to fish muscle tissue. Each solvent addition follows homogenization using a waring blender. After evaporation of the solvent, total extracted lipids are determined in the (lower) chloroform phase. A modification of this rather laborious procedure by Carlson [43] uses dichloromethane-methanol $(2: 1, \mathrm{v} / \mathrm{v})$ in the extraction of serum and liver tissue giving results identical to chloroform-methanol, an advantage being the lower toxicity of dichloromethane.

Over the past decades, hexane-propan-2-ol $(3: 2, \mathrm{v} / \mathrm{v})$ mixtures have frequently and effectively been used for lipid extraction from animal tissues, due to their lower toxicity and reduced costs compared to chloroform and methanol, as described by Hara and Radin [44]. According to Furusawa et al. [45] total lipids are efficiently extracted from egg yolk with $n$-hexane-acetonitrile (2:1, $\mathrm{v} / \mathrm{v}$ ) for the determination of organochlorine pesticides (OCPs) $\mathrm{HCH}$, aldrin, dieldrin, DDT, DDD and DDE.

Another prominent method is the 3-step procedure developed in 1999 by Smedes [46] after restrictions on the use of chlorinated solvents such as chloroform or dichloromethane under the 1987 Montreal Protocol [47] required an alternative. Following similar principles as Bligh and Dyer [42], Smedes replaced chloroform with the apolar solvent cyclohexane and extracted lipids from marine tissues using a propan-2-ol:cyclohexane:water $(8: 10: 11, \mathrm{v} / \mathrm{v} / \mathrm{v})$ mixture. To $10 \mathrm{~g}$ of sample containing $8 \mathrm{~g}$ water, $16 \mathrm{~mL}$ of 2 -propanol and $20 \mathrm{~mL}$ cyclohexane are added, and the mixture dispersed with an Ultra-Turrax disperser for $2 \mathrm{~min}$. After adding $14 \mathrm{~g}$ of water the mixture is dispersed for $1 \mathrm{~min}$, followed by centrifugation. Due to its lower density, the cyclohexane separates at the top of the extraction mixture and can therefore be easily recovered. Extraction is repeated one more time and supernatants are combined and reduced to dryness. When compared with the Bligh and Dyer [42] method, lipid extraction efficiency was found to be $6 \%$ higher for herring, but 8 and $4 \%$ lower for plaice and mussel, respectively.

It should be noted that "classical" methods for lipid extraction as developed by Lovern [6], Christie [36], Folch [39], Bligh and Dyer [42], Hara and Radin [44], or Smedes [46] predominantly focused on determination of the lipid composition in tissue of fish and vertebrates, rather than on quantification of lipophilic contaminants.

The Jensen extraction method [48] for total lipids and lipophilic pollutants in aquatic organisms such as fat or lean fish yields recoveries that are not significantly different from the Folch and Bligh and Dyer methods. The 3-step procedure involves (1) propan-2-ol-diethyl ether (DEE), (2) $n$-hexane/DEE and propan-2-ol, and (3) $n$-hexane/DEE.

Löfgren's "BUME method" $[49,50]$ extracts lipids from small amounts of plasma $(10-100 \mu \mathrm{L})$ and from pulverized freeze-dried heart or liver samples $(15-150 \mathrm{mg}$ ) using butanol:methanol $(3: 1, \mathrm{v} / \mathrm{v})$ in an automated homogenization procedure, followed by a second extraction step with the same solvent mixture. Extraction efficiency was determined by the addition internal standards prior to extraction. When compared to the Folch procedure, this method yields comparable or slightly better results for most tested lipids, but significantly improved results for a number of phospholipids.

Speer and co-workers [51] extracted 205 pesticides with cyclohexane:ethyl acetate (1:1, v/v) from egg and milk samples using an Ultra-Turrax tube drive. After cooling to $-20{ }^{\circ} \mathrm{C}$, adding a mixture of $\mathrm{NaCl}$, sodium citrate-dihydrate, disodium hydrogen citrate-sesquihydrate and magnesium sulphate, followed by shaking and centrifugation, target analytes were quantified with $\mathrm{GC} /$ MS-MS and LC/MS-MS. Recoveries were found to be generally higher than that achieved with the "QuEChERS" multi-method [52].

The Soxhlet apparatus, designed in 1879 by the agricultural chemist Franz Ritter von Soxhlet, allows for continuous solid-liquid extraction of lipids from (marine) animal tissues with various solvent systems. These include: toluene-hexane [53], acetone-petroleum [54], MTBE [55, 56], cyclohexane-acetone-petroleum ether [57], methylene chloride-hexane [58], hexane-acetone $[59,60], n$-hexane $[61,62]$ and acetone-dichloromethane [63]. However, extraction results of the same sample 
often vary between laboratories due to the use of different solvent mixtures, numbers of cycles and/or boiling periods $(6-24 \mathrm{~h})$. The amount of time needed, large solvent volumes required (120-400 mL per sample) and subsequent losses of volatile and semivolatile species during concentration of extracts (for instance, up to 20\% for highly chlorinated benzenes, depending on the evaporation method used), are among the main disadvantages of Soxhlet extraction [64]. Although boiling, rinsing and solvent recovery were eventually automated and optimized, efficiency is generally lower than that of the Bligh and Dyer [42] and Smedes [46] methods, because a considerable fraction of "bound lipids" are not extracted, and results are not considered as total lipids but as "extractable" lipids [46]. While Soxhlet extraction for $24 \mathrm{~h}$ using acetone:hexane (1:3, v/v), when compared to Smedes' method, showed reduced extraction efficiency for plaice $(-30 \%)$ and mussel $(-20 \%)$, results with herring were comparable [46].

Twisselmann's continuous hot extraction [65] overcomes this drawback, providing increased extraction temperature by hot solvent vapour flowing through the extraction thimble from below. This not only improves lipid solubility and extraction efficiency also for "bound lipids", but reduces extraction time by up to $50 \%$. The solvent is collected separately during the process, eliminating the evaporation step. These features make the Twisselmann technique, especially when integrated in an automated extraction device, more resource-efficient [66]. As an example, this method has been used to extract lipids from freeze-dried (marine) animal tissue, egg or milk samples with ethanol:toluene (70:30, v/v) during a boiling period of 6-8 h [67], while another study [68] used ethyl acetate:cyclohexane $(1: 1, \mathrm{v} / \mathrm{v})$ for extraction of lipids from fish tissue (extraction time not given). As an alternative to freeze-drying, samples may be treated with a drying agent (e.g. super absorbent polymer, SAP) prior to extraction.

Accelerated solvent extraction (ASE) [69], or pressurized liquid extraction (PLE), combines elevated pressures and temperatures above the boiling point with smaller amounts $(10-50 \mathrm{~mL}$ per sample [64]) of the same solvents or mixtures that are commonly used for standard liquid extraction techniques (Soxhlet or Twisselmann), such as dichloromethane-hexane [70], dichloromethane-cyclohexane [71], or methanol [72]. In an automated process, the solvent is pumped into a sealed tube with sample and support material. After a suitable time, it is pumped out and collected, then the procedure is repeated several times. The total extraction time is just $10-40 \mathrm{~min}$ [64]. However, the apparatus and equipment are rather expensive and solvent mixtures, temperatures and pressures must be adjusted for each sample type to ensure extraction of all free fat, while bound lipids may still not be extracted sufficiently [38]. The wash procedure of the extraction cells is also quite complicated and results in a significant increase in solvent consumption [73]. ASE was originally developed and tested for solid and semi-solid samples. Recoveries of polycyclic aromatic hydrocarbons (PAHs) from urban dust and marine sediment samples and of PCBs from sewage sludge and oyster tissue are reported as quantitative [69]. ASE may further be applied for lipid extraction from (marine) animal tissue [74-77], egg containing foods [78] or dairy products [79]. Chloroform-methanol, hexane-propane-2-ol, or methylene chloride have been used to extract fish tissue [74], egg yolk can be extracted with propan-2-ol:hexane $(2: 3, \mathrm{v} / \mathrm{v})$ [75], egg-containing foods with chloroform:methanol $(2: 1, \mathrm{v} / \mathrm{v})$ and hexane:propan-2-ol (3:2, v/v) [76], and poultry tissue with chloroform:methanol $(2: 1, \mathrm{v} / \mathrm{v})[75$, 76]. For ASE of various dairy products, Richardson [79] used mixtures of two or three of the following solvents: hexane, petroleum ether, dichloromethane, methanol, ethanol, propan-2-ol and acetone. Castro-Gómez et al. [41] performed ASE with dichloromethane-methanol $(2: 1, \mathrm{v} / \mathrm{v})$ as solvent mixture at $60^{\circ} \mathrm{C}$, a pressure of 10.3 $\mathrm{MPa}$ and two cycles of $5 \mathrm{~min}$ each to extract total lipids from raw whole milk from cows, sheep and goats. While extraction efficiency was significantly higher than with the "Folch-method", it was identical for cow's milk, $5 \%$ less for sheep's milk and $8 \%$ less for goat's milk than what was achieved with the rather laborious reference methods according to ISO 14156/IDF 172 [80] or RöseGottlieb [81].

Based on Baron Charles Cagniard de la Tour's discovery of the phenomenon of supercritical fluids in 1822, supercritical fluid extraction (SFE) generally uses supercritical carbon dioxide $\left(\mathrm{sCO}_{2}\right)$, which is particularly suitable for the extraction of non-polar compounds. The critical temperature of $\mathrm{CO}_{2}\left(31.1{ }^{\circ} \mathrm{C}\right)$ is close to ambient making SFE convenient for heat-sensitive (biological) compounds, and its low critical pressure (7.39 MPa) allows operation with moderate pressures [82]. The density of the $\mathrm{sCO}_{2}$ at around 200 bar $(20 \mathrm{MPa})$ is similar to that of $n$-hexane, as are the solvation properties that allow it to act as a non-polar solvent [83]. Near the supercritical region, $\mathrm{CO}_{2}$ can dissolve triacylglycerols at concentrations up to $1 \%$ mass [83]. Extraction is complete within 15 min up to several hours, depending on sample type and target compounds. The solvent is easily removed by making them sub-critical through pressure reduction and/or temperature adjustment. A co-solvent, such as ethanol or methanol, may be added as a modifier. For example, Tanaka et al. [84] demonstrated that at $33{ }^{\circ} \mathrm{C}$ and $17.7 \mathrm{MPa}$ only $65 \%$ of triacylglycerols and no phospholipids were extracted from freeze-dried fish roe 
when using pure $\mathrm{CO}_{2}$, while $100 \%$ of triacylglycerols and more than $80 \%$ of phospholipids were obtained by adding $20 \%$ ethanol to the solvent. In general, SFE seems to provide a significantly higher extraction efficiency than Bligh and Dyer's extraction method, while an increase in proportion of modifier in the solvent composition enhances extraction efficiency for phospholipids [85]. In SFE of lipids and cholesterol from fish muscle, extraction efficiency was not significantly enhanced by increasing $\mathrm{CO}_{2}$ pressure and/or temperature, but primarily by prolonging the extraction period from 3 to $9 \mathrm{~h}$ [86]. However, ethanol as an entrainer significantly enhanced lipid extraction at each pressure applied. $\mathrm{sCO}_{2}$, and $\mathrm{sCO}_{2}$ plus ethanol, removed $78 \%$ and $97 \%$ of the lipids, and 97\% and $99 \%$ of the cholesterol, respectively, from trout muscle [86]. Sánchez-Camargo et al. [87] reported similar findings in SFE of lipids from shrimp. Snyder et al. [88] extracted lipids together with heptachlor, dieldrin and endrin from pre-dried peritoneal fat, breast, leg and thigh tissue, and liver from chickens by SFE, and by solvent extraction using petroleum ether. Recoveries of organochlorine pesticides by SFE extraction were equivalent to those obtained by conventional extraction with petroleum ether except for liver, for which recoveries from SFE extraction were significantly higher. The main advantage of SFE is the easy manipulation of fluid density and thus its solvating power, which results in improved fractionation capability. With $\mathrm{CO}_{2}$ being nonflammable, inexpensive, nontoxic and readily available, SFE has helped to eliminate the use of solvents such as $n$-hexane, chloroform or methylene chloride. Drawbacks of SFE include the complex phase equilibrium of the solvent/solute system and, through addition of co-solvents for the extraction of polar compounds, complication of further downstream sample processing. Capital costs and costs for running the multipart equipment process are high [82], so SFE is likely to be used only where there are significant advantages.

\section{Implications for European official food control}

This brief review suggests that depending on (1) sample matrix properties, (2) the nature of lipids to be extracted, (3) the type and extent of lipid binding, (4) the degree of association of lipophilic POPs to different classes of tissue lipids, (5) solvent properties and composition, and (6) the efficiency of the selected technology, both the extracted fractions of different lipid classes and the results for lipid-associated environmental POPs may vary considerably. Frequently observed unsatisfactory extraction efficiency due to insufficient and inconsistent release of POPs tightly associated with various covalently bound lipids cannot always be compensated by adding internal standards (IS) to the sample prior to the preparation and extraction steps. The basic assumption with internal standardization that any losses should affect the IS and target analyte proportionally, so the ratio of analyte to IS stays constant, proves most likely inapplicable in such cases and the approach not effective at improving method performance and data quality. Consequently, suchlike losses translate more or less directly into a significant bias and/or imprecision of the analytical results, affecting both intra- and inter-laboratory reproducibility and accuracy.

For instance, target compounds within European official control of dioxins and PCBs in various foods of animal origin are the 29 most toxicologically relevant PCDD/F and PCB congeners. After uptake and distribution among different tissue compartments, they associate with the various types of lipids present within each tissue, depending on their respective physico-chemical properties. However, besides free lipids, and lipids with weak or moderately strong affinity, lipids reversibly and non-covalently associated with specific intracellular lipid-binding proteins, tissue fat in the liver of farmed animals, fish meat and fish liver contains considerable fractions of covalently bound phospholipids (up to $90 \%$ of total lipids) varying with age and between species. The outcome of bioanalytical, enzyme inhibition or enzymelinked immunosorbent assay methods or of the rather complex and cost-intensive physico-chemical multi-residue analysis may therefore fail to reflect the actual relative composition (congener-pattern or "fingerprint") of toxic organic pollutants present in the tissue or sample. The illustrated scenario could also pose a substantial risk of generating results in official food control that underestimate the actual levels of lipid-associated POPs to which the consumer to be protected is in reality exposed.

False-compliant (false-negative) results could then be a consequence when checking compliance of samples with specific legal limits such as EU action levels [89] (ALs), serving as warning levels, and maximum levels [90,91] (MLs) for PCDD/Fs and PCBs (Table 1), or maximum residue levels [92] (MRLs) for fat-soluble OCPs. This potential threat to consumer's health is of significance especially where EU legislation has established ALs and MLs on wet weight basis requiring laboratories performing official control of the levels of contaminants such as PCDD/Fs and PCBs in food to report results on wet weight basis. In dioxin and PCB analysis, this is the case for liver of terrestrial animals including sheep [91], and for meat and liver of farmed fish and farmed fishery products $[89,90]$ (Table 1 ). Only if the result, expressed on wet weight basis, is above the respective wet weightbased $\mathrm{ML}\left(\mathrm{ML}_{\mathrm{ww}}\right)$ beyond a reasonable doubt, the sample is declared "non-compliant" with EU food legislation [2]. As a direct consequence, products of concern are 
Table 1 Action levels and maximum levels established by current EU legislation [89-91] for PCDD/Fs and DL-PCBs in food of animal origin; WHO-TEQs (Toxic EQuivalents), fat: based on fat content, ww: based on wet weight

\begin{tabular}{|c|c|c|c|c|c|}
\hline \multirow[t]{2}{*}{ Food sample } & \multicolumn{2}{|l|}{ Action level $^{a}$} & \multicolumn{2}{|c|}{ Maximum level } & \multirow{2}{*}{$\begin{array}{l}\text { Unit } \\
\mathrm{pg} / \mathrm{g}\end{array}$} \\
\hline & DL-PCB-TEQ & PCDD/F-TEQ & PCDD/F-TEQ & $\begin{array}{l}\text { PCDD/F-PCB- } \\
\text { TEQ }\end{array}$ & \\
\hline Bovine and sheep meat, products thereof & 1.75 & 1.75 & 2.5 & 4.0 & Fat \\
\hline Poultry meat, products thereof & 0.75 & 1.25 & 1.75 & 3.0 & Fat \\
\hline Pig meat and products thereof & 0.50 & 0.75 & 1.0 & 1.25 & Fat \\
\hline Terrestrial animal liver and products thereof & & & 0.30 & 0.50 & wW \\
\hline Sheep liver and products thereof & & & 1.25 & 2.00 & $w W$ \\
\hline Fish meat (farmed) and products thereof & 2.50 & 1.50 & 3.5 & 6.5 & wW \\
\hline Eel meat and products thereof & & & 3.5 & 10.0 & wW \\
\hline Fish liver and products thereof & & & & 20.0 & wW \\
\hline Marine oils & & & 1.75 & 6.0 & Fat \\
\hline Raw milk, dairy products including butter fat & 2.00 & 1.75 & 2.5 & 5.5 & Fat \\
\hline Hen's eggs and products thereof & 1.75 & 1.75 & 2.5 & 5.0 & Fat \\
\hline Bovine and sheep fat and products thereof & & & 2.5 & 4.0 & Fat \\
\hline Poultry fat and products thereof & & & 1.75 & 3.0 & Fat \\
\hline Pig fat and products thereof & & & 1.0 & 1.25 & Fat \\
\hline Mixed animal fats & 0.75 & 1.00 & 1.5 & 2.50 & Fat \\
\hline Foods for infants and young children & & & 0.1 & 0.2 & wW \\
\hline
\end{tabular}

${ }^{a}$ Action levels based on fat (pg TEQ/g fat) are not applicable for food products containing $<2 \%$ fat

withdrawn from the market, a measure with potentially significant (financial) implications. Table 1 shows, however, that in most cases, MLs and ALs for dioxins, PCBs and/or for the sum of dioxins and PCBs are based on the fat content because dioxins accumulate in the fatty tissue of the animals, and in egg and milk fat [89-91]. Only when samples contain less than $2 \%$ fat does EU food legislation require that a $\mathrm{ML}$ based on wet weight $\left(\mathrm{ML}_{\mathrm{ww}}\right)$ must be calculated from the respective fat-based ML $\left(\mathrm{ML}_{\mathrm{fat}}\right)$, being $\mathrm{ML}_{\mathrm{ww}}=\mathrm{ML}_{\mathrm{fat}} \times 0.02$ [91].

Efficiency of lipid extraction from animal tissue may often be subject to strong variations difficult to control with internal standards and significantly affecting the reproducibility of lipid-based analytical results, both between and even within laboratories. Randall et al. [93] observed variations of up to a factor of 3.5 for the results of extracted lipids during a collaborative study evaluating different solvents and methods for lipid extraction. An explanation for such rather dramatic scatter seems that certain types of lipids get "trapped" in small domains or are covalently bound to proteins, as is the case, e.g. for phospholipids. The latter are present in substantial but varying species-, sex- and age-specific proportions in terrestrial animal liver, as well as in meat and liver of fish. Lipid-associated contaminants seem to be more easily extractable than these trapped or bound lipids, the extraction of which may-depending on the procedure applied-not only be deficient but of unsatisfactory reproducibility, as well. A one-to-one relationship between extracted lipids and the lipophilic contaminants, which may not be as evenly distributed within the sample tissue to be analysed as the analyst would like them to be, should therefore not be anticipated. Consequently, environmental lipophilic POPs may show considerable variability in fat-based results, generally expressed as relative standard deviation (RSD) under within-lab $\left(\mathrm{RSD}_{\mathrm{Rw}}\right)$ and between-lab reproducibility conditions $\left(\mathrm{RSD}_{\mathrm{R}}\right)$. It is also not entirely surprising that the same results obtained from the same samples but based on wet weight appear more homogeneous with significantly lower $\mathrm{RSD}_{\mathrm{Rw}}$ and $\mathrm{RSD}_{\mathrm{R}}$ values [94].

Recognizing these observations, the European Commission in accordance with the opinion of the Standing Committee on the Food Chain and Animal Health (SCoFCAH) changed in Regulation (EU) No 1067/2013 [91] the reference base of MLs, and ALs (only for meat of farmed fish and products thereof), from "fat" to "wet weight". Paragraphs (8) and (9) state that "in order to ensure comparable results and an uniform enforcement approach across the Union as regards to dioxins and PCBs in liver of terrestrial animals, it is appropriate to establish the maximum levels on a wet weight basis as was already established for fish liver and derived products thereof." In line with this modification, the respective MLs for PCDD/Fs and for the sum of PCDD/Fs and DL-PCBs in terrestrial animal liver were changed from 
$4.5 \mathrm{pg} \mathrm{WHO}-\mathrm{PCDD} / \mathrm{F}-\mathrm{TEQ} / \mathrm{g}$ fat and $10.0 \mathrm{pg} \mathrm{WHO}-$ PCDD/F-PCB-TEQ/g fat [90], to $0.30 \mathrm{pg}$ WHO-PCDD/ F-TEQ/g ww and $0.50 \mathrm{pg}$ WHO-PCDD/F-PCB-TEQ/g ww [91], respectively. Although the nominal values of the MLs are now smaller by a factor of 15 , and 20, respectively, this change actually represents an increase in both MLs for any farmed animal's liver (except sheep) containing less than $6.7 \%$, and $5 \%$ lipids, respectively, by up to a factor of 5, as stated by the German Federal Institute for Risk Assessment (BfR). For the first time, individual MLs were introduced for dioxins and PCBs in sheep's liver and derived products, exceeding by a factor of 4 the MLs set for liver of terrestrial animals (Table 1). Having assessed the health implications of the new MLs, the BfR concluded that even the consumption of $250 \mathrm{~g}$ of sheep liver containing dioxins and DL-PCBs in the range of the new MLs on a single occasion may lead to the tolerable weekly intake (TWI) being exceeded [95]. The BfR further recommends that consumers in Germany generally avoid the consumption of sheep liver [95]. In summary, insufficient reproducibility of fat-based results from methods for extraction of lipids and lipophilic pollutants applied within official control lead to a significant increase in MLs and considerable consequences for the affected population's diet.

In the case of fish, however, other reasons for choosing wet weight as reference base were pivotal. The European Commission's Scientific Committee on Food (SCF) assessed in 2000 the dietary exposure of the general population of EU member states [96, 97]. This assessment was based on the "Final Report of Scientific Cooperation" (EU SCOOP) [98] containing a large set of PCDD, PCDF, and DL-PCB concentrations in many foods of 10 participating countries. Frequency distributions of the contamination levels based on extracted lipids across 1995-1999 showed, that ranges in fish span over two (for DL-PCBs) to three (for PCDD/Fs) orders of magnitude, which is readily explained by the large variety of species taken into account. Severely skewed distributions of PCDD/Fs $\left(x_{\min }=0.125, \bar{x}=9.80,95 \%\right.$ ile $=79.0$, $99 \%$ ile $=188 \mathrm{pg} \mathrm{I-TEQ} / \mathrm{g}$ fat $)$ and DL-PCBs $\left(x_{\min }=1.61\right.$, $\bar{x}=30.7,95 \%$ ile $=148,99 \%$ ile $=285$ pg PCB-TEQ $/ g$ fat $),$ respectively, reflect the remarkable dispersion of lipidbased concentrations in fish, which are between one and two orders of magnitude larger than those in other foods [96]. For example, the 95th percentile value serving as cut-off point for risk management, which would keep on the market $95 \%$ of the samples, is 37 times higher for $\mathrm{PCDD} / \mathrm{Fs}$ in fish (79.0 pg I-TEQ/g fat) compared to terrestrial animals (2.11 pg I-TEQ/g fat). As levels of lipophilic POPs in fish depend on species, fat content, the extent of migration of wild fish, the number of spawning cycles, age, site, and feeding habits [99], the SCF concluded that for better comparability, maximum levels should preferably be expressed on wet weight basis [96].

Within the scope of our tasks as European Union Reference Laboratory (EU-RL) for Dioxins and PCBs in Feed and Food (2006-2017), following Article 32 of Council Regulation (EC) 882/2004 [100], we organized bi-annual proficiency testing (PT) studies aiming to ensure highquality, uniform testing throughout the EU. The above described measures to improve reproducibility of results from analysis of dioxins and PCBs in fish meat was for the first time put to the test in 2011, when National Reference Laboratories (NRLs) and official laboratories of EU member states were requested to participate in a PT study on determination of PCDD/Fs and PCBs in salmon filet. 28 NRLs representing $25 \mathrm{EU}$ member states and 63 official laboratories (OFLs) from $10 \mathrm{EU}$ member states participated. Salmon filet samples were prepared from salmon from the Lulea archipelago in the Baltic Sea, kindly provided by the Swedish NRL. Participants used their own reference standards and the bioanalytical and/or physico-chemical (GC/HRMS) confirmatory methods of their choice. Applied extraction procedures included, but were not limited to, Bligh and Dyer and Smedes methods, Soxhlet and Twisselmann hot extraction, ASE (PLE) and SFE, with or without modifications in solvents and solvent combinations. Consensus values were calculated according to the IUPAC protocol [101] after excluding extreme outliers as Huber's robust means [102], and they were used as assigned values. For extracted lipids ("lipid content"), the assigned value was $6.2 \%$, however, we found large differences between laboratories $\left(\mathrm{RSD}_{\mathrm{R}}=34 \%\right)$. Although $80 \%$ of extracted lipid results were within the $\pm 20 \%$ range of the assigned value, $8 \%$ were beyond the $\pm 20 \%$ range yet within $\pm 30 \%$ range, while $12 \%$ of the lipid results were more than $30 \%$ below the assigned value (of which $7.5 \%$ were more than $50 \%$ below the assigned value).

Participants' lipid-based results for 17 individual 2,3,7,8-substituted PCDD/Fs, 12 DL-PCBs and 6 marker PCBs were clearly dependent on the amount of extracted fat and thus on the extraction method and/or solvents applied. Almost expectedly, the levels of PCDD/Fs and PCBs expressed on wet weight basis were more comparable. Assigned values for sum-parameters were $3.68 \mathrm{pg}$ WHO-PCDD/F-TEQ/g ww, 6.03 pg WHO-PCB-TEQ/g ww, $9.76 \mathrm{pg}$ WHO-PCDD/F-PCB-TEQ/g ww, and $35.3 \mathrm{ng} / \mathrm{g}$ ww for the sum of marker PCBs. For PCDD/ Fs, DL-PCBs, the sum of PCDD/Fs and DL-PCBs, and the sum of marker PCBs, $83-90 \%$ of reported wet weight-based results were within a range of $\pm 20 \%$ of the assigned value ( $\mathrm{z}$-scores within the \pm 2 range). Consequently, $10-17 \%$ were beyond the $\pm 20 \%$ range, some z-scores even outside of the \pm 5 range (beyond $\pm 50 \%$ of 
the assigned value). This distribution of wet weight-based analytical results obviously reflects that described for the extracted lipids. To our surprise, a tendency to underestimate the sum of DL-PCBs, the sum of PCDD/Fs and DLPCBs, and the sum of marker PCBs in salmon filet was noticeable in results submitted from NRLs. For results submitted for PCDD/Fs, the performance of NRLs and official laboratories was comparable. Taking into account the respective expanded measurement uncertainties (U), $43 \%$ of participating laboratories reported exceedance of the ML for the sum of PCDD/Fs and DL-PCBs (in 2011, this ML was set to $8.0 \mathrm{pg}$ WHO-PCDD/F-PCBTEQ/g ww [90]) and 57\% reported no exceedance. While $56 \%$ of participating laboratories reported exceedance of the PCDD/F-AL (in 2011, the AL was set to $3.0 \mathrm{WHO}$ $\mathrm{PCDD} / \mathrm{F}-\mathrm{TEQ} / \mathrm{g}$ ww [103]), and $44 \%$ of participants reported no exceedance. This clearly shows that assigned concentrations about $20 \%$ above the respective ML, or $\mathrm{AL}$, may lead to about $50 \%$ of NRLs and official control laboratories assessing their analytical results as "exceeding the ML", or "exceeding the AL", while the remaining $50 \%$ of laboratories declare the same sample "compliant".

We conclude that expression of results for lipophilic pollutants in fish meat on wet weight basis does not necessarily ensure acceptable inter-laboratory variability of lipid contents and concentrations of target analytes, and consistent assessment of compliance with EU maximum and action levels. Based on the extraction procedures applied during the PT, certain POPs conceivably closely associated with covalently bound or "trapped" lipids can be removed from the sample matrix only to a limited and varying extent. Whether analytical results are expressed on wet weight or on lipid basis, foods of animal origin generally require complete, reproducible extraction of both the lipids and the lipophilic analytes of interest.

\section{Present study}

Within the scope of establishing strong EU-wide analytical standards, the Bioassay Research Unit at the European Union Reference Laboratory (EU-RL) for Dioxins and PCBs in Feed and Food (Freiburg, Germany) has, in co-operation with the Department of Environmental Toxicology, University of California Davis (Davis, USA), evaluated and optimized the performance of bioanalytical screening methods for suitability within European official food control [104-106]. As a result of new developments in sample preparation, we present a rapid, efficient and selective procedure for removal of "total" lipids and lipophilic organic pollutants from any EU-regulated [89-91] food of animal origin. Starting out from Smedes' method [64] for determination of lipids in fish and vertebrates, Ultra-Turrax assisted matrix dispersion was modified to facilitate desorption of "total" lipids and lipophilic
POPs such as dioxins and PCBs from adipose tissue, fish, fish oil, liver, meat, chicken eggs, egg powder, whole milk, milk powder, milk products and infant food. Optimization and validation of this method was performed using a combination of instrumental and aryl hydrocarbon receptor (AhR)-based cell bioassay analysis.

\section{Methods \\ Chemicals \\ Cyclohexane, $n$-hexane (for rinsing of glassware) and propan-2-ol, each of grade 'Dioxins, Pesti-S, Furans, PCBs analysis' used for lipid extraction were from Bio- solve (Valkenswaard, Netherlands), double-distilled water $\left(\mathrm{ddH}_{2} \mathrm{O}\right)$ was from Roth (Karlsruhe, Germany).}

\section{Glassware}

When dioxins and PCBs were analysed after determination of lipids, cleaned laboratory glassware was baked at $435^{\circ} \mathrm{C}$ for $18 \mathrm{~h}$ (overnight), and after cooling to ambient temperature the glassware was kept covered or stored in a suitable container. Shortly before use, the glassware was rinsed three times with $n$-hexane and briefly allowed to dry. All glassware was loosely covered with aluminium foil throughout sample processing.

\section{Samples}

Samples in this study were obtained from regular market food, contamination incidents and PT studies, and included: adipose tissue (bovine, pig), liver (bovine, sheep), meat (bovine, pig, sheep, poultry), fish, fish oil, cow's milk, milk powder, milk fat, butter, and chicken eggs. Lipids were extracted from freeze-dried sample material using Twisselmann hot extraction [65] at the Chemical and Veterinary Investigation Office (CVUA) Freiburg's physico-chemical routine lab for dioxin analysis, part of which functioned as $E U-R L$ for Dioxins and PCBs in Feed and Food. PCDD/F and DL-PCB levels were determined by GC/HRMS confirmatory analysis and results expressed as WHO-PCDD/F-TEQ, WHOPCB-TEQ and WHO-PCDD/F-PCB-TEQ. TEQ results obtained for adipose tissue, liver, meat, fish, fish oil and chicken eggs ranged from slightly below the respective limit of quantification (LOQ) up to twice the ML and/ or the AL set by EU legislation [89-91] (Table 1). These samples were used as reference materials in validation and QC studies as required by Commission Regulation (EU) 2017/644 [2] involving comparison of the individual TEQ values with cell bioassay-based bioanalytical screening results of the same sample, expressed in bioanalytical equivalents (BEQ) [2]. Further included in this study were human milk samples obtained from 8 countries (Australia, Brazil, China, Spain, Fiji, Ireland, Philippines and USA) during the third WHO Global Survey on POPs 
(2000-2003) [107] and pre-analysed at CVUA's routine dioxin laboratory also functioning as WHO Reference Laboratory. Solid samples were homogenized in a waring blender to ensure representative subsamples and stored in a freezer below $-25^{\circ} \mathrm{C}$ prior to extraction.

\section{Modified Smedes extraction (MSE) of "total" lipids}

Frozen (pre-homogenized) samples were thawed to ambient temperature and re-homogenized before weighing in a glass bottle (Duran glass bottle, $100 \mathrm{~mL}$ or $250 \mathrm{~mL}$, Schott, Mainz, Germany). The analytical sample weight should be chosen according to requirements, such as certain amounts of lipids to be extracted, or expected concentrations of POPs to be quantified. See Table 2 for exemplary sample weights and corresponding solvent volumes, which need to be adjusted if other sample weights are chosen. Dry egg powder was soaked in an aliquot of $\mathrm{dd}_{2} \mathrm{O}$ (for $76 \%$ water content) prior to extraction. Lipids were also extracted from fats and oils of animals and fish before clean-up, as this often results in reduced background signals. With the exception of fat, oil and dry matrices (e.g. egg or milk powder), for sample weights below $5 \mathrm{~g}$ the corresponding solvent volumes should not be further reduced. All solvents were dispensed from bottle-top dispensers.

An aliquot propan-2-ol was added and the mixture briefly swirled to avoid sample material sticking to the glass wall, or clumping. Then cyclohexane was added and the mixture was briefly homogenized using an Ultra-Turrax $^{\circledR}$ disperser (IKA T25, IKA, Staufen, Germany) with an $18 \mathrm{~mm}$ dispersing element (IKA S25N$18 \mathrm{G})$ at $10.000 \mathrm{rpm}$; dispersing times are presented in Table 2. After addition of $\mathrm{ddH}_{2} \mathrm{O}$, the ternary solventmatrix mixture was dispersed for $15 \mathrm{~s}(30 \mathrm{~s}$ for meat and fat). Table 3 shows fresh sample weight, average lipid and water contents, and the individual propan-2-olcyclohexane-water ratios for each sample, taking into account its average water content, prior to "Ultra-Turrax B" dispersion (Table 2).

With 5-10 mL propan-2-ol, sample remains adhering to the dispersing element were rinsed into the upper solvent layer. If necessary, horizontal circular swirling of the vessel on a flat surface by hand for a few seconds (Table 2) supported phase separation while re-mixing of already separated phase volumes was avoided. The lower aqueous phase, or remnants of an emulsion that may remain suspended between aqueous and organic layers, should not be allowed to re-mix with the upper cyclohexane layer. We observed spontaneous phase separations within less than $30 \mathrm{~s}$ for chicken eggs (Fig. 1), re-constituted egg powder, fats, meat (ruminants, poultry), fish oil, whole milk, milk powder, milk fat, butter and commercial infant foods. The upper phase was transferred into an evaporation glass tube using an accu-jet ${ }^{\circledR}$ pro pipette controller with adjustable speed (Brand, Wertheim, Germany) equipped with a glass pipette.

For fish and liver tissue, a sufficiently large cyclohexane phase equal or greater than $25 \%$ of the added volume of cyclohexane did not always separate during the first extraction, even with prolonged swirling. Depending on lipid content, nature and composition, only a few $\mathrm{mL}$ of a clear upper phase may have formed, while a distinct cloudy mixed phase (emulsion) remained suspended between the aqueous and organic layers. In this instance, another $5-10 \mathrm{~mL}$ of propan-2-ol were carefully added to the emulsion. Swirling for a few seconds and let stand for 2-3 min resulted in clearer solvent and separation, where $25 \%$ or more of previously added cyclohexane could be collected as described above.

Extraction was repeated twice with additional cyclohexane (Table 2), once only for fish oil, and three times for fish and liver tissue if phases did not separate properly during the first extraction. The mixture was dispersed for $10 \mathrm{~s}$, or $15 \mathrm{~s}$ if fat or meat were extracted. Cyclohexane phases again separated spontaneously within less than $30 \mathrm{~s}$ during repetitions, while for fish and liver tissue this process required up to $2 \mathrm{~min}$ for complete separation. The collected organic phases were reduced to dryness in a TurboVap II concentrator workstation (Biotage, Uppsala, Sweden). An outline of the modified Smedes [46] extraction (MSE) procedure is shown in Fig. 2.

If the dried extract was to be submitted for clean-up to follow-up POPs analysis, mild conditions were chosen (water bath: $45-50{ }^{\circ} \mathrm{C}$, nitrogen: 0.6 bar) to minimize evaporation losses particularly of the semi-volatile dioxin-like coplanar PCB 126. The extract was weighed, dried for $30 \mathrm{~min}$, or overnight (the vessel loosely covered with alumina foil), weighed again and the drying repeated if necessary until the weight remained constant. Alternatively, last traces of solvent were removed by placing the evaporation glass tubes in a drying oven at $103{ }^{\circ} \mathrm{C}$ for 45 to 60 min until-after cooling to ambient temperaturethe extract weight remained constant. The lipid content was calculated from the weight of the dry residue and the initial weight of the analytical sample.

Note: In routine analysis it is advisable to use an individual dispersing element for each sample, so that samples can be extracted in sequence within each extraction step while the time-consuming cleaning between individual sample/solvent-mixtures and the risk of cross-contamination can be avoided. Then the time required for the entire extraction process will not exceed 8 min per sample for fish and liver and $6 \mathrm{~min}$ for all other matrices. It is time saving to initially subject all samples of a series in sequence to the first extraction. Solvent evaporation in the concentrator should commence for all extracts 


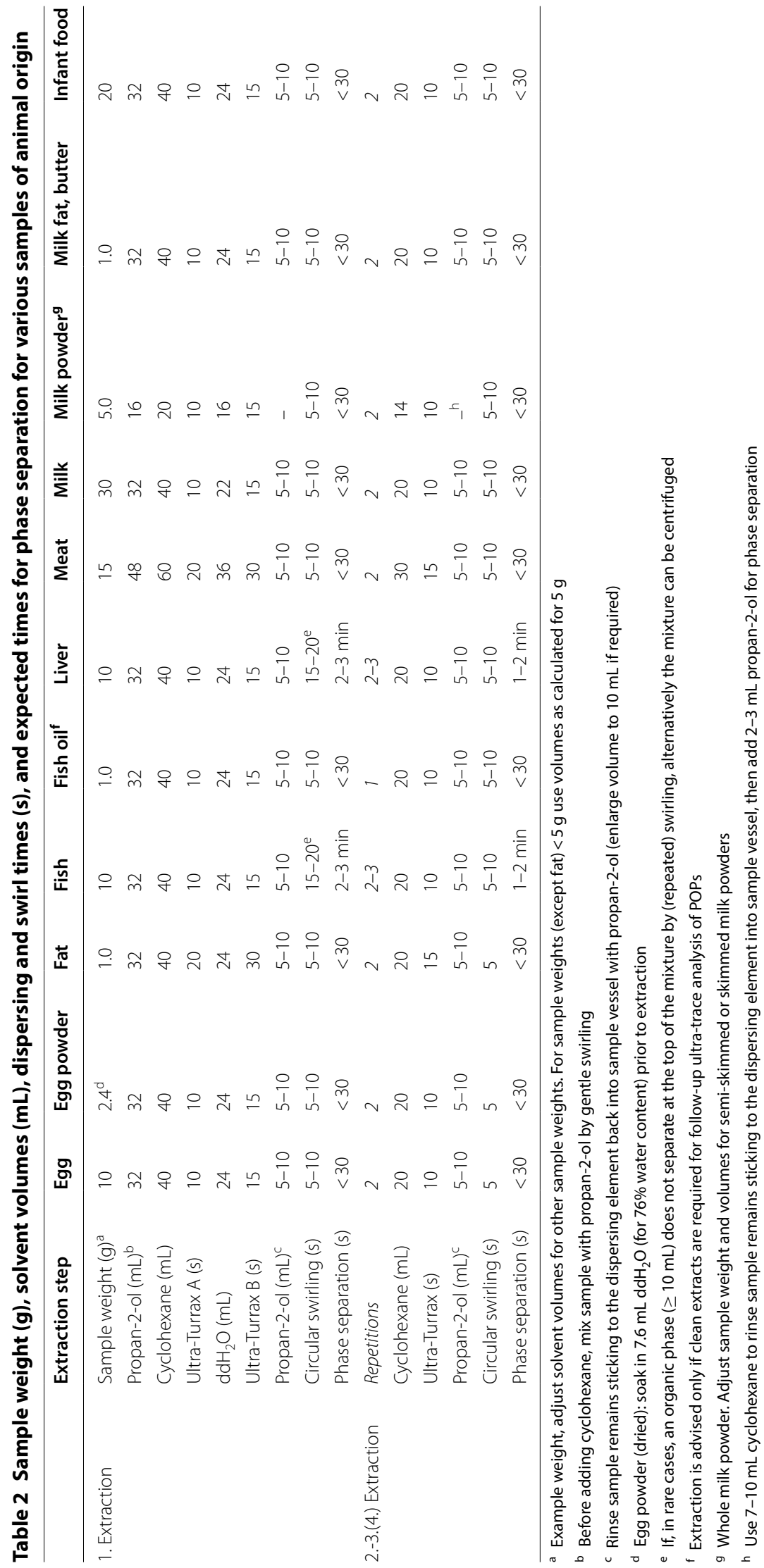


Table 3 Fresh sample weight, average lipid and water contents, and propan-2-ol-cyclohexane-water ratios taking into account the average sample water content (in $\mathrm{mL}$, and normalized to cyclohexane $=10$; v/v/v), during the first extraction prior to "Ultra-Turrax B" (Table 2)

\begin{tabular}{|c|c|c|c|c|c|c|c|}
\hline \multirow[t]{2}{*}{ Sample matrix } & \multirow[t]{2}{*}{$\begin{array}{l}\text { Fresh } \\
\text { sample } \\
\text { weight (g) }\end{array}$} & \multirow[t]{2}{*}{ Lipid content $^{\mathrm{a}}(\mathrm{g})$} & \multirow[t]{2}{*}{$\begin{array}{l}\text { Water content } \\
(\mathrm{mL})\end{array}$} & \multicolumn{2}{|c|}{$\begin{array}{l}\text { Propan-2-ol- } \\
\text { cyclohexane-water ratio } \\
\text { (v/v/v) }\end{array}$} & \multirow[t]{2}{*}{$\begin{array}{l}\text { Fresh sample } \\
\text { weight, } \\
\text { normalized }^{\text {b }}\end{array}$} & \multirow[t]{2}{*}{$\begin{array}{l}\text { Lipid content, } \\
\text { normalized }^{\text {b }}\end{array}$} \\
\hline & & & & $(\mathrm{mL})$ & normalized $^{\mathbf{b}}$ & & \\
\hline Hen's egg & 10 & $1.0(10 \%)$ & $7.6(76 \%)$ & $32: 40: 31.6$ & $8: 10: 8$ & 2.5 & 0.25 \\
\hline Egg powder, reconstituted ${ }^{c}$ & 10 & $1.0(10 \%)$ & $7.6(76 \%)$ & $32: 40: 31.6$ & $8: 10: 8$ & 2.5 & 0.25 \\
\hline Fat, melted & 1.0 & 1.0 (99\%) & $0.0(<0.2 \%)$ & $32: 40: 24$ & $8: 10: 6$ & 0.25 & 0.25 \\
\hline Fish (freshwater, marine) ${ }^{d}$ & 10 & $0.6(6.2 \%)$ & $7.4(74 \%)$ & $32: 40: 31.4$ & $8: 10: 8$ & 2.5 & 0.15 \\
\hline Fish oil & 1.0 & $1.0(100 \%)$ & $0.0(0.0 \%)$ & $32: 40: 24$ & $8: 10: 6$ & 0.25 & 0.25 \\
\hline Liver (beef, veal, pork) ${ }^{d}$ & 10 & $0.4(4.3 \%)$ & $7.2(72 \%)$ & $32: 40: 31.2$ & $8: 10: 8$ & 2.5 & 0.10 \\
\hline Meat (beef, pork, poultry) ${ }^{d}$ & 15 & $0.5(3.3 \%)$ & $11(75 \%)$ & $48: 60: 47$ & $8: 10: 8$ & 2.5 & 0.08 \\
\hline Milk & 30 & $1.1(3.5 \%)$ & $26(88 \%)$ & $32: 40: 48$ & $8: 10: 12$ & 7.5 & 0.275 \\
\hline Whole milk powder & 5.0 & $1.3(26 \%)$ & $0.2(3.5 \%)$ & $16: 20: 16.2$ & $8: 10: 8$ & 2.5 & 0.65 \\
\hline Milkfat & 1.0 & $1.0(98 \%)$ & $0.0(1.1 \%)$ & $32: 40: 24$ & $8: 10: 6$ & 0.25 & 0.25 \\
\hline Butter & 1.0 & $0.8(82 \%)$ & $0.2(17 \%)$ & $32: 40: 24.2$ & $8: 10: 6$ & 0.25 & 0.20 \\
\hline Infant food ${ }^{e}$ & 20 & $1.1(5.7 \%)$ & $9.0(45 \%)$ & $32: 40: 33$ & $8: 10: 8$ & 5.0 & 0.275 \\
\hline
\end{tabular}

a Average values for lipid and water content in the sample, Swiss Food Composition Database (V6.0) [108]

b Normalized to 10 parts by volume cyclohexane (rounded) for comparison with Smedes [46] (8:10:11, v/v/v)

c $2.4 \mathrm{~g}$ dry egg powder was reconstituted with $7.6 \mathrm{~g} \mathrm{ddH}_{2} \mathrm{O}$ before extraction

d Average values

e Sample was: "Baby organic menu tomato rice with fine organic turkey"

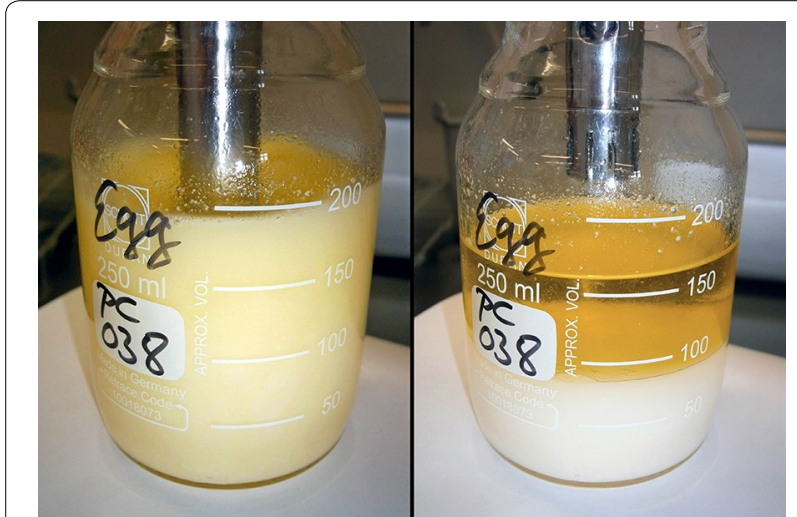

Fig. 1 Modified Smedes extraction (MSE) of "total" lipids. Left: $15 \mathrm{~s}$ dispersion of $10 \mathrm{~g}$ chicken egg with $32 \mathrm{~mL}$ propan-2-ol, $40 \mathrm{~mL}$ cyclohexane and $24 \mathrm{~mL}$ water ("Ultra-Turrax B" in Table 2); right: $30 \mathrm{~s}$ after rinsing the rotor-stator with 5-10 $\mathrm{mL}$ propan-2-ol and brief circular swirling on a flat work surface. The clear upper organic phase was collected with a glass pipette connected to a pipette controller

simultaneously after completion of the first extraction. The use of two concentrator workstations simultaneously for 12 sample extracts allows the entire evaporation process to be completed within 60 to $90 \mathrm{~min}$. The time required for total lipid extraction from 12 samples of animal origin from weigh-in to the dried extract is $3.0 \mathrm{~h}$ for fish and liver, and $2.5 \mathrm{~h}$ for all other matrices.
Propan-2-ol:cyclohexane:water ratios $(\mathrm{v} / \mathrm{v} / \mathrm{v})$, fresh sample weight $(\mathrm{w})$ and lipid $(\mathrm{w})$ ratios normalized to 10 parts by volume cyclohexane $(\mathrm{v}=10)$ for all sample matrices of interest are depicted in Fig. 3.

\section{Clean-up of extracts}

Purification of the crude extract represents an important step in removing unwanted co-extractives that can potentially interfere with GC/HRMS measurement or alter the response in the AhR-based cell bioassays used in this study. For example, the clean-up procedure for screening analysis of PCDD/Fs and DL-PCBs is briefly described: Up to $2 \mathrm{~g}$ of dry lipid extract were re-dissolved in $15 \mathrm{~mL} n$-hexane. The solution was freed of lipids on $33 \%$ sulphuric acid activated silica $(1: 2, \mathrm{w} / \mathrm{w})$, followed by fractionated elution of the target compounds from an $1 \%$ activated carbon/celite (1:99, w/w) mixture. PCDD/F and DL-PCB eluates were reduced and transferred to conical $1.2 \mathrm{~mL}$ vials. The volume was carefully reduced to $2-3$ $\mu \mathrm{L}$. In a final step, the remaining solvent was exchanged for $7 \mu \mathrm{L}$ of DMSO in the case of the PCB-fraction, and for $14 \mu \mathrm{L}$ of DMSO in the case of the dioxin-fraction, following a well-established procedure keeping vialto-vial variability, expressed as relative standard deviation (RSD), below 5\%. The smaller volume for the final extract containing DL-PCBs was chosen due to a reduced 


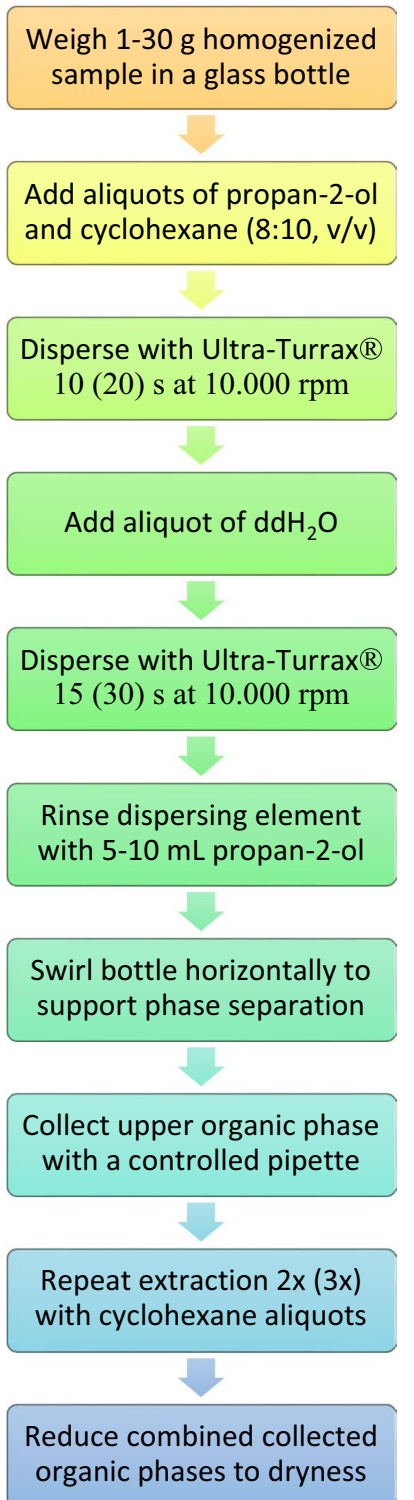

Fig. 2 Outline of the modified Smedes [46] extraction (MSE) of lipids from foods of animal origin. Figures in brackets () apply to fish meat and liver. For more details see Table 2

relative potency (REP), or response of the cell bioassay to PCB 126, the most abundant DL-PCB, being approximately $40 \%$ relative to the assay's response to the most potent compound, 2,3,7,8-tetrachlorodibenzo- $p$-dioxin $(2,3,7,8-\mathrm{TCDD})[105,109-111]$.

\section{Bioanalytical screening for PCDD/Fs and DL-PCBs}

Relative quantitation of 2,3,7,8-TCDD and related dioxinlike chemicals (PCDDs, PCDFs and PCBs) in sample extracts was performed using the Chemically Activated $L U$ ciferase eXpression (CALUX) recombinant cell bioassay, which is based on the molecular mechanism by which the AhR mediates the toxic and biological effects of these compounds [112, 113]. First described in 1996 by Denison and coworkers [114, 115], the CALUX bioassay typically utilizes recombinant mouse (H1L6.1c3) and rat (H4L1.1c4) cell lines that contain a stably integrated AhR-responsive firefly luciferase gene plasmid as the detection system [112]. Exposure of these cells to standard solutions or extracts containing 2,3,7,8-TCDD and/ or other AhR-active compounds results in a time-, doseand chemical-specific and AhR-dependent induction of luciferase expression, which can be readily measured by light output in an enzymatic reaction [112, 114, 116, 117]. More recently, an amplified third generation CALUX rat cell line (H4L7.5c2) was developed and the firefly luciferase plasmid contains 20 dioxin-responsive elements (compared to the 4 contained in the plasmids in earlier CALUX lines) and these cells exhibit a significantly greater overall induction response and lower detection limit than previous cell lines [118]. Mouse (H1L6.1c3) and rat (H4L1.1c4 and H4L7.5c2) and other CALUX cell lines are freely available for non-profit research purposes and can be obtained from Prof. Denison, Department of Environmental Toxicology, University of California, Davis, CA 95616. These cells are also available for commercial and government screening purposes through a licensing agreement with the Hiyoshi Corporation, Omihachiman, Japan (www.calux-jp.com/english/).

Mouse (H1L6.1c3) or rat (H4L1.1c4 and H4L7.5c2) cells were seeded into 96-well culture plates and incubated at $37{ }^{\circ} \mathrm{C}$ in the presence of $5 \% \mathrm{CO}_{2}$ for $24 \mathrm{~h}$. Individual concentrations of a TCDD standard dilution series and sample extracts (all in DMSO) were added to incubation medium and the mixtures subsequently transferred to the cells in triplicate. After incubation at $33{ }^{\circ} \mathrm{C}$ in the presence of $5 \% \mathrm{CO}_{2}$ for 24-48 h (depending on the cell line used), the cells were lysed, followed by addition of D-luciferin (Duchefa, Haarlem, The Netherlands), the substrate for the bioluminescence reaction of firefly luciferase. Incubations were carried out at $33{ }^{\circ} \mathrm{C}$ during the exposure period rather than at $37^{\circ} \mathrm{C}$ because incubation at the lower temperature has been demonstrated to result in a significant increase in overall luciferase activity [119]. Luciferase activity was measured as emitted light (luminescence) from each well, expressed in relative light units (RLUs), in a Centro LB 960 microplate luminometer (Berthold, Bad Wildbad, Germany). The magnitude of induction of luciferase activity is directly related to the level of reporter gene expression and proportional to the total concentration of TCDD-like AhR activators in the standard solution or extract. This correspondence follows a classical ligand-receptor binding curve. When plotted in a semi-log graph, the concentration-response 


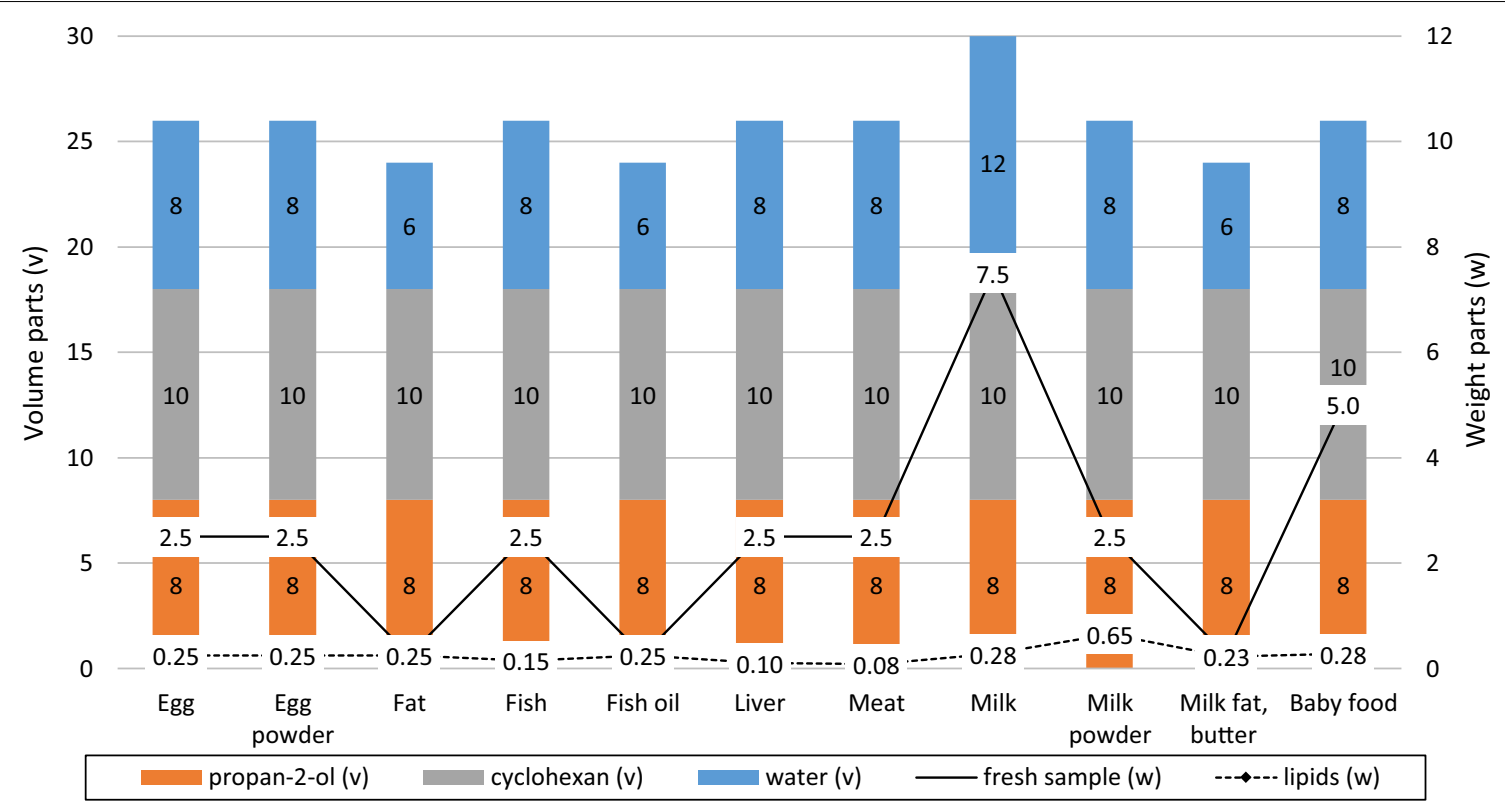

Fig. 3 Propan-2-ol:cyclohexane:water ratios $(\mathrm{v} / \mathrm{v} / \mathrm{v})$, fresh sample weight $(\mathrm{w})$ and lipid $(\mathrm{w})$ ratios. Data normalized to 10 parts by volume cyclohexane $(\mathrm{v}=10)$ for all matrices included; egg powder: sample weight parts refer to dry powder reconstituted with dd $\mathrm{H}_{2} \mathrm{O}$ prior to extraction (Table 3)

data adopt a sigmoidal shaped pattern to which most commonly a 4-parameter logistic (4PL) function is fit. Hill's equation [120] being mathematically analogous to the logistic equation is frequently used for this purpose. Details on fitting concentration-response curves are described elsewhere [106]. The unknown concentration of the analyte(s) may now be determined by comparing the cell response measured in the assay to the fitted TCDD standard curve. Sample-based results (in BEQs) were calculated taking into account sample intake and final extract volume and subsequently corrected for the procedural blank and the apparent recovery of the positive control sample analysed with each sample series.

The bioanalytical method used within this study has been fully validated for all sample matrices of interest according to the requirements given in Commission Regulation (EU) 2017/644 [2] and applied under a strict GC/ HRMS-backed quality control (QC) scheme [104-106].

\section{Reporting bioanalytical results}

The bioanalytical results presented are not shown with an associated measurement uncertainty (MU) expressed as expanded uncertainty $(U)$ according to ISO/IEC Guide 98-3:2008, part 3 [121], and reported as an interval $x \pm U$ corresponding to a particular level of confidence, such as 95\%. While Commission Regulation (EU) 2017/644 [2] requires reporting of TEQs obtained from confirmatory analysis together with the respective MU for decision over sample compliance with regulatory limits,
BEQs from bioanalytical screening must be compared to pre-established cut-off values based on a normal distribution approach and acceptable $\alpha$ - and $\beta$-errors $[2,106]$. Ensuring a false-compliant rate below 5\%, these cut-offs take into account the MU associated with results from confirmatory analysis, variability and apparent recovery of bioanalytical results at ML (or AL), and the sensitivity of the bioanalytical method [2, 106]. A sample with a BEQ-result above the cut-off is "suspected to be noncompliant" requiring follow-up confirmatory analysis to determine sample TEQs for final decision. Otherwise, the sample is declared "compliant" with immediate legally binding force. It follows that a "non-compliant" result can only be obtained by confirmatory analysis and the MU is therefore only required for that purpose.

This approach is in line with the IUPAC definition of "uncertainty of measurement" being "a parameter associated with the result of a measurement that characterizes the dispersion of the values that could reasonably be attributed to the measurand" [122], i.e. the quantity intended to be measured [123]. "The specification of a measurand requires knowledge of the kind of quantity, description of the state of the phenomenon, body, or substance carrying the quantity, including any relevant component, and the chemical entities involved" [123]. The analyst must therefore decide a priori on the compounds to be analysed. Once the "measurand" has been defined, it cannot be changed during the measurement process, 
since a goal for a measurement must not become a moving target in the course of that process [124].

The CALUX bioassay measures the overall response of the cell to chemical exposure and not individual chemical concentrations. Although highly selective [105], it is not $100 \%$ specific for the toxicologically relevant 29 $\mathrm{PCDD} / \mathrm{Fs}$ and DL-PCBs of interest. Other AhR agonists, which despite all precautions may have made their way through the extraction and clean-up procedures into the final sample extract, and survived metabolism during cell incubation, may, in principle, contribute to the overall response [105]. Due to the possible cross-reactivity of the bioassay with unknown AhR active compounds, it is not possible to decide, before starting the analysis, what exactly will be measured. It follows that we cannot define the measurand and MU cannot be calculated for bioanalytical results, which are therefore-in line with the definition of "measurement result" [123]_expressed as a single measured value. Also based on the concept of a pre-defined measurand are the IUPAC definitions of "bias" and "random error" [125]. When presenting our validation results, we therefore chose the "method comparison bias" instead of the "systematic error" or "bias" as defined by IUPAC. It should be noted that the above considerations can apply to other screening assays as well.

\section{Results and discussion}

\section{Reference methods, materials and database}

Twisselmann hot extraction [65] combining extraction efficiency and moderate solvent consumption is one of the methods proposed in the recent UNEP Guidance Document on the Global Monitoring Plan for Persistent Organic Pollutants under the Stockholm Convention [126] to support comparability and consistency of monitoring results. Twisselmann extraction has also been selected as the method of choice by CVUA Freiburg's routine dioxin lab running GC/HRMS confirmatory methods, being tightly linked to the EU-RL for Dioxins and PCBs in Feed and Food (since 08.02.2018 "EU-RL for Halogenated Persistent Organic Pollutants in Feed and Food"), and sharing analytical methods and infrastructure. Solvents used were cyclohexane:toluene (1:1, $\mathrm{v} / \mathrm{v}$ ) for adipose tissue, liver, meat, fish and chicken eggs, $\mathrm{n}$-hexane for raw milk, and ethanol:toluene $(70: 30, \mathrm{v} / \mathrm{v})$ for homogenized milk and milk products (e.g. butter, cheese). Boiling period was 6-8 h. Fat extracted from homogenized milk was further purified by re-dissolving in MTBE thus separating insoluble components. In all samples, CVUA's dioxin routine lab had previously quantified extractable lipid contents and the levels of individual PCDD, PCDF and DL-PCB congeners using methods approved by the EU-RL for Dioxins and PCBs in Feed and Food, thus providing an excellent and comprehensive reference database for comparison with the amounts of lipids extracted by MSE (this work) and the bioanalytical results measured from the same samples in our Bioassay Research Lab.

\section{Ultra-Turrax ${ }^{\circledR}$ assisted dispersion}

Converting immiscible solvents such as water and cyclohexane together with a pre-homogenized food sample into a dispersion, thereby reducing particle sizes and disrupting cell membranes or the native macrostructure of milk fat globules is a crucial step in the extraction process. Ultra-Turrax assisted high-speed dispersion provides a fast and effective method for disintegration of animal tissue or foods of animal origin in a ternary solvent mixture, in which polar, medium-polar and non-polar solvents are equally distributed. Material suspended in the media is exposed to tearing, shear fluid forces and cavitation [127], the interaction of which rapidly disperses, homogenizes, emulsifies, cuts, crushes and disintegrates. Resulting particle size distributions between 4 and $10 \mu \mathrm{m}$ [128] considerably increase the overall solvent-accessible surface area. The rotor of the dispersing element acts as a centrifugal pump to recirculate the liquid and suspended solids by drawing them axially into the dispersion head and then forcing them radially through the ports of the stationary stator into the surrounding mixture. A decline of the low pressure near the rotor's inlet below the saturated vapour pressure of the liquid results in the formation of small vapour-filled cavities. The dispersion carries these "cavitation bubbles" to the surrounding high-pressure area in front of the blades, where they rapidly and violently collapse. This process may result in very high energy densities and in very high local temperatures and local pressures at the surface of the bubbles for a very short time [129]. Rapidly imploding bubbles send out shock waves and form tiny but powerful high-pressure micro-jets of fluid holding a tremendous amount of kinetic energy. When these micro-jets and shock waves hit mammalian cells, they damage and disrupt the cell walls and membranes resulting in an enhanced solvent penetration into the cells and an intensification of mass transfer. The destructive effect of cavitation on mammalian tissue cells down to the subcellular level has been described elsewhere [130]. "Free" lipids and lipids moderately attached or covalently bound and associated lipophilic POPs are released and are now easily available for transition to the organic phase. UltraTurrax dispersion of whole milk induces damage and break-up of the MFGMs enveloping the milk fat globules, releasing the di- and triacylglycerols as the main components from their core. 


\section{Solvent mixture composition}

Our goal was an extensive removal of all lipid classes from each EU-regulated [89-91] food sample of animal origin-mainly phospho- and glycolipids, fatty acids, sterols, acylglycerols, etc. A low polarity solvent such as cyclohexane will remove most of non-polar lipids (sterols, acylglycerols), while polar lipids are removed with a medium polar solvent such as propan-2-ol which will also assist in disrupting van der Waals forces or hydrogen bonds between lipid head groups of "bound lipids" and proteins (chapter 1.3). Smedes [46] successfully introduced this approach for lipid extraction from marine tissues, in which a ternary solvent mixture with relative polarities of its components ranging from 0.006 (cyclohexane) to 0.546 (propan-2-ol) to 1.000 (water) was applied. In the liquid-liquid extraction procedure, propan-2-ol being mixable with water and to some extent soluble in cyclohexane will decrease the polarity of water and increase the polarity of unipolar solvent.

In an initial study, for which we selected fish, bovine liver, bovine meat, chicken eggs and whole milk, the method was to be extended and optimized for the extraction of other samples of animal origin. Following Smedes' approach, a mixture of $16 \mathrm{~mL}$ propan-2-ol, $20 \mathrm{~mL}$ cyclohexane, $14.5 \mathrm{~mL}$ water and $10 \mathrm{~g}$ of homogenized sample (assuming a general sample water content of $7.5 \mathrm{~mL}$ ) was dispersed with an Ultra-Turrax at $10,000 \mathrm{rpm}$. The ratio of cyclohexane to fresh sample weight being 2:1 (v/w), the overall solvent ratio was $8: 10: 11(\mathrm{v} / \mathrm{v} / \mathrm{v})$. The presence of considerable amounts of surfactant-like compounds such as triglycerides, free fatty acids, phospholipids, proteins, etc., lowering the surface tension between water, water-soluble matrix compounds and the organic solvents, often led to the formation of rather stable emulsions above a clear water phase. Such emulsions are particularly common in samples where the diet of the source animal is high in fat [131], which is why we included high-fat bovine meat in our studies. Emulsions not only make quantitative collection of the phase of interest difficult, they can also trap some of the target analyte(s). The classical method for disrupting emulsions by adding salt(s) or salt water to increase the ionic strength of the aqueous phase with subsequent shaking and several minutes of standing time appeared too time consuming for a high-throughput routine laboratory. Centrifugation as employed by Smedes [46] can easily take up to $20 \mathrm{~min}$ to complete and should therefore also be avoided if possible. Freezing the water layer to cause phase separation is both time-consuming and less effective here, since the emulsion to be separated is already located above a clear layer of water consisting mainly of cyclohexane, propan-2-ol and disintegrated sample material.
Unfortunately, the straightforward approach of increasing the volume of one solvent or another to achieve separation was not successful.

We therefore changed the ratio of cyclohexane to the fresh sample mass to $4: 1(\mathrm{v} / \mathrm{w})$ for fish, bovine liver, bovine meat and chicken eggs and $32 \mathrm{~mL}$ propan-2-ol, $40 \mathrm{~mL}$ cyclohexane and $44 \mathrm{~mL}$ water (including $7.5 \mathrm{~mL}$ water in the sample) were used, while the overall solvent ratio remained 8:10:11 (v/v/v). First propan-2-ol, then cyclohexane and, after brief homogenization of the mixture, finally the water should be added to the weighed sample. This prevents the sample material from sticking to the glass wall of the vessel, or clumping. For meat and milk, the sample size was eventually increased to $15 \mathrm{~g}$, and $30 \mathrm{~g}$, respectively (Table 2) to ensure that the extracted lipid amounts were sufficient $(>0.2 \mathrm{~g})$ for the subsequent analysis of POPs, even in samples with lower fat content. While keeping the cyclohexane volume constant, the volumes of the propan-2-ol and water fractions were systematically varied and phase separation and lipid extraction efficiency for fish, bovine liver, bovine meat and chicken eggs proved best when using an 8:10:8 (v/v/v) propan-2-ol:cyclohexane:water mixture with a significantly reduced water fraction (Table 3). For milk, however, the optimal solvent ratio was found to be $8: 10: 12$ $(\mathrm{v} / \mathrm{v} / \mathrm{v})$. After dispersion of each matrix, phase separation was facilitated by rinsing the rotor-stator device with 7-8 mL propan-2-ol, which we let carefully pass into the organic layer, followed by gentle circular swirling of the vessel on the worktop to complete phase separation. The additional amount of propan-2-ol changes the overall propan-2-ol-cyclohexane-water ratio effective at phase separation (Table 3).

Following this procedure, distinct phase separation spontaneously occurred with meat, egg and milk dispersions within less than $30 \mathrm{~s}$ and lipid extraction was complete after two repetitions (Table 2). In liver and most frequently in fish, dispersions phase separation required up to three minutes and even then was incomplete. In such cases, a few more $\mathrm{mL}$ propan-2-ol were added directly to the emulsion formed between the aqueous and organic layers with a pipette. This small amount of propan-2-ol appeared to adjust the solvent properties for separation, causing surfactant-like compounds to dissolve more readily in either the organic or aqueous layer, which helped break up the emulsion. Repeated circular swirling generally allowed $25-30 \%$ of the previously added cyclohexane volume to be collected while three repetitions were required for complete extraction of the "total" lipids and lipophilic POPs from liver or fish tissue, during which phases separated spontaneously. An increase of the propane-2-ol volume by the same 7-8 mL already before sample dispersion, however, had 
no supporting effect on the separation of the cyclohexane layer. If, in rare cases, still less than $25 \%$ of the previously added cyclohexane can be removed in the first extraction, the analyst may, as is routinely required in Smedes' method [46], resort to the rather time-consuming centrifugation of the mixture at $450-480 \times g$.

The method was extended to fat, fish oil, milk fat, butter and similar sample matrices, reducing the water fraction to a solvent ratio of $8: 10: 6(\mathrm{v} / \mathrm{v} / \mathrm{v})$, and to various commercial infant foods, for which the solvent ratio of 8:10:8 (v/v/v) exhibited optimal performance.

\section{Extraction efficiency}

We evaluated the efficiency of each consecutive extraction by applying the enhanced procedure described in this paper to five basic types of foods of animal origin considered analytically challenging in terms of texture, complexity, lipid and protein composition, release of lipids and targeted POPs, emulsion formation or co-extraction of interfering compounds. For sample amounts, solvent volumes and composition see Tables 2 and 3. Lipid extraction profiles were established in duplicate under within-lab reproducibility conditions for prehomogenized chicken eggs, fish (brown trout), bovine liver, bovine meat (beef neck), and for cow's whole milk (Fig. 4). The results presented are only examples and may vary depending on the width of the extraction vessel affecting the layer thickness of the formed phases, the extent of emulsion formation, if any, and the pipetting technique. Total extracted lipids are compared in Fig. 5 with the results of Twisselmann's hot extraction [65] serving as a "reference" method within this study.

Cow's whole milk Within just $15 \mathrm{~s}$ of dispersion of $30 \mathrm{~g}$ milk with an 8:10:12 (v/v/v) propane2-ol:cyclohexane:water mixture at 10,000 rpm, more than $90 \%$ of the "total" lipids entered the cyclohexane phase. The subsequent two extractions yielded $6-8 \%$, and below $2 \%$, respectively. The cyclohexane separated spontaneously on top of the mixture following each dispersion. Total extracted lipids ( $4.2 \%$ of the fresh sample weight) corresponded well with results from the Twisselmann extraction (4.3\%). The high efficiency and precision of our modified Smedes extraction (MSE) was confirmed within the scope of verifying the authenticity of organic milk using stable isotope analysis [132]. The results are in good agreement with those obtained from the Röse-Gottlieb reference method [81] but are available much faster.

Chicken eggs Despite the emulsifying properties of phosphatidylcholine and lecithin contained in the egg yolk and the egg white's albumin protein component, $82 \%$ of all extracted lipids were obtained after dispersing the egg sample for $15 \mathrm{~s}$ with an 8:10:8 (v/v/v) propane2-ol:cyclohexane:water mixture and spontaneous separation of a clear upper phase. Compared to Smedes method [46], the mixture contained a considerably reduced fraction of water. A further $13-14 \%$, and about $5 \%$, of total extracted lipids were obtained during the first and second subsequent extractions. Compared to Twisselmann extraction $(8.5 \%)$ the fraction of total extracted lipids was

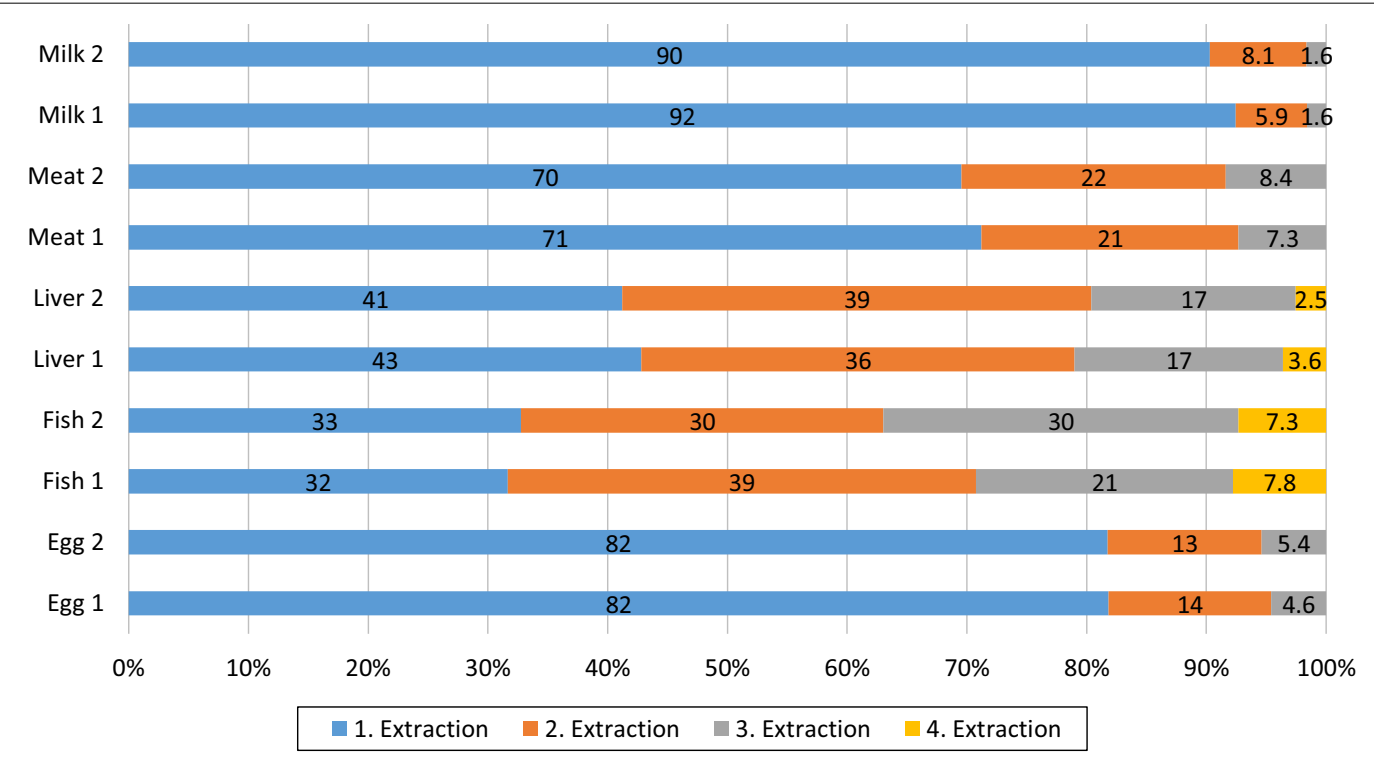

Fig. 4 Lipid extraction profiles (in duplicate) from applying the modified Smedes [46] extraction (MSE, this work) under within-lab reproducibility conditions for chicken eggs, fish meat (brown trout), bovine liver, bovine meat (beef neck) and cow's whole milk. Amounts are given in \% of total extracted lipids 


\section{2}

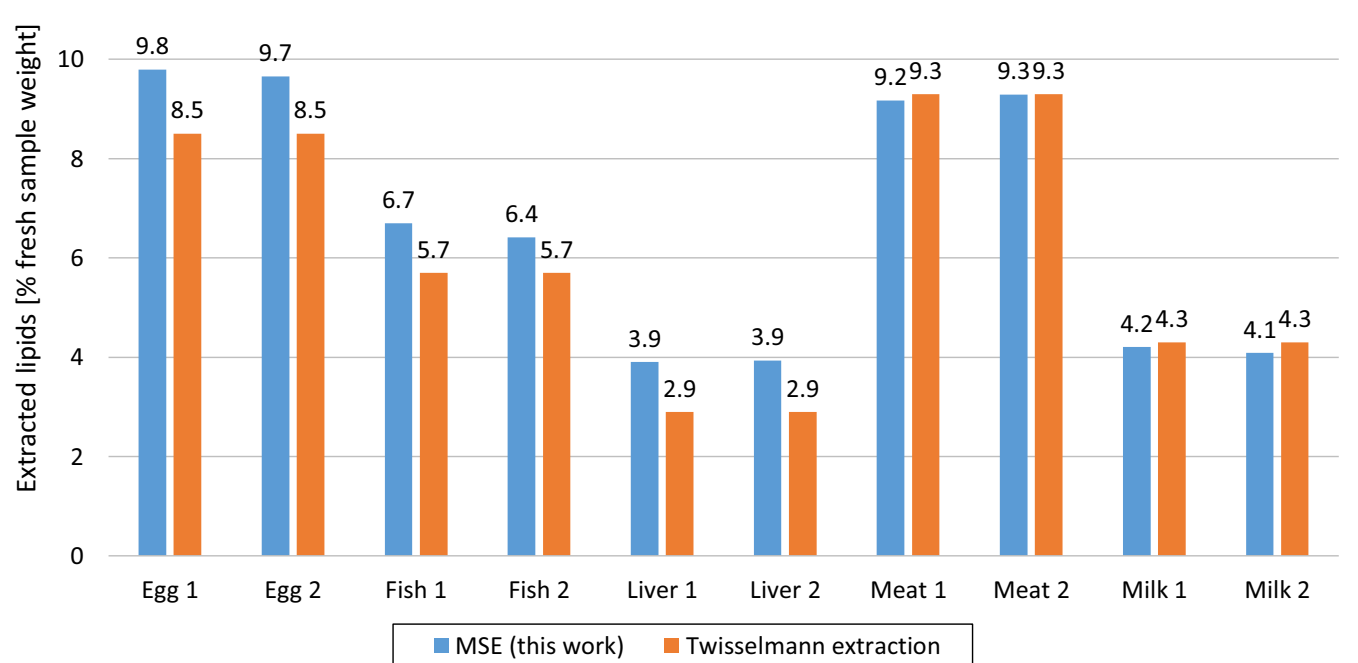

Fig. 5 Comparison of "total" lipids (in \% ww) extracted in duplicate from selected food matrices by applying the modified Smedes [46] extraction (MSE, this work) and Twisselmann [65] extraction

significantly increased (9.8\%) and close to the expected value (10\%) provided by the Swiss Food Composition Database [108]. We conclude that the tiny non-covalent lipoprotein structures in egg yolk-LDL measuring $35-40 \mathrm{~nm}[12,133]$ and HDL 8-12 nm [134] in diameter-are as readily opened-up and destroyed by cavitation and shearing forces as the 100 times larger milk fat globules measuring approximately $4 \mu \mathrm{m}$ in diameter [135].

Bovine meat Although pre-homogenized, the fibrous nature of skeletal muscle renders this tissue more resistant to destruction and therefore more difficult to disperse. The release of lipids from the crushed lipid-rich beef neck tissue with propane-2-ol:cyclohexane:water $(8: 10: 8, \mathrm{v} / \mathrm{v} / \mathrm{v})$ required $30 \mathrm{~s}$ of high-performance dispersion. While $70 \%$ of extracted lipids were released into the first extract, slightly more than $20 \%$ were obtained with the second and $7-8 \%$ with the third extract. Total extracted lipids (9.3\%) are in perfect agreement with results from Twisselmann hot extraction (9.3\%).

Bovine liver After applying the Ultra-Turrax disperser for $15 \mathrm{~s}$ at $10,000 \mathrm{rpm}$ to a mixture of bovine liver and propane-2-ol:cyclohexane:water $\quad(8: 10: 8, \quad \mathrm{v} / \mathrm{v} / \mathrm{v}), \quad$ an emulsion frequently formed suspended between the aqueous and cyclohexane phases with only a few $\mathrm{mL}$ clarified organic phase separated on top. The emulsion was reduced and the cyclohexane phase enlarged by carefully adding several more mL propan-2-ol to the emulsion with a glass pipette and circular swirling. Occasionally, only $25-30 \%$ of the previously added cyclohexane volume was collected during the first extraction and a significantly smaller portion of total extracted lipids (this work: approximately 42\%) was obtained. However, this did not diminish the overall recovery provided by a fourth extraction. In this instance, 36-39\% of "total" lipids were found during the second extraction, $17 \%$ during the third, and $2.5-3.5 \%$ during the fourth extraction. With $3.9 \%$ of the fresh sample weight, the total fraction of extracted lipids was significantly greater than that from Twisselmann extraction (2.9\%).

Fish meat Dispersing fish muscle tissue with propane2-ol:cyclohexane:water $(8: 10: 8, \mathrm{v} / \mathrm{v} / \mathrm{v})$ for $15 \mathrm{~s}$ frequently formed a rather stable emulsion above the aqueous layer, considerably lowering the extraction efficiency of the lipids into the organic phase. The presence of hydrophobic and hydrophilic amino acids in myofibrillar proteins favours gelation, water holding and emulsion formation by bridging water and oil-fat droplets through the decrease in their surface tension. Differing myofibrillar protein concentrations among various fish species result in variations in their emulsifying ability. After rinsing the rotor-stator with propan-2-ol several additional $\mathrm{mL}$ of this medium polar solvent were added to the cloudy mixed phase with a pipette to interfere with the pronounced sorption of cyclohexane by the dispersed fish meat. Repeated circular swirling supported separation of approximately $25 \%$ (or sometimes less) of the previously added cyclohexane volume on top of the emulsion within three minutes. Three repetitions, each generally with spontaneous phase separation were required for complete extraction of the "total" lipids and lipophilic POPs. The yields from the first duplicate extraction were low but reproducible with $32 \%$ and $33 \%$ of the total extracted 
lipids. From the first and second repetitions, we received $30 \%$ and $39 \%$, and $30 \%$ and $21 \%$, respectively. Individual results differed considerably due to some variability in emulsion breaking, pipetting and cyclohexane volumes recovered. Reproducibility was excellent however, if the summarized results obtained during the second and third extractions are compared (60\% each). Another 7.5\% of the total extracted lipids were collected in the fourth extraction. The $6.6 \%$ total lipids extracted with our MSE method exceeded the results obtained from the Twisselmann [65] procedure (5.7\%) by $16 \%$.

In summary, efficiency in the extraction of bovine meat and whole milk is comparable for both methods, while for chicken eggs, brown trout and bovine liver our enhanced method is much more effective than hot extraction according to Twisselmann (Fig. 5), specifically by $14 \%$ for eggs and fish and by $34 \%$ for liver. Comparison of the total lipids extracted in duplicate from 8 retail fish samples (zander, pike, whitefish, four bream, one fried fish) using the method described in this paper along with the lipid results from Twisselmann, supports these results (Fig. 6). Exceptions are a bream ("Bream2") and the whitefish, the former with $28 \%$ more lipids obtained by Twisselmann's hot extraction, the latter with comparable results using both methods.

To assess extract purity, we re-dissolved the dried lipid extracts obtained from chicken eggs, fish (brown trout), bovine liver, bovine meat (beef neck) and cow's whole milk in $n$-hexane as is done for further clean-up, resulting in clear solutions. A powdery insoluble residue remained at the bottom of the flask. In the case of eggs, meat and milk, it was white and weighed less than $1 \mathrm{mg}$. Insoluble residues from fish and liver extracts were white or brownish-grey in colour and weighed less than $28 \mathrm{mg}$, which on the basis of $10 \mathrm{~g}$ fresh sample weight would theoretically lead to an underestimation of the analytical results by $0.28 \%$. Compared to the gain in extraction efficiency, which was $14 \%$ for fish and $34 \%$ for liver, these small amounts were negligible.

\section{Intermediate precision and method comparison bias}

Twelve different EU-regulated [89-91] food samples were subjected to multiple extraction, nine of which were extracted 10 times and three samples extracted 5 times, under within-laboratory reproducibility conditions. Table 4 lists individual results, mean values and dispersion parameters (minimum, maximum, $\mathrm{SD}, \mathrm{RSD}_{\mathrm{Rw}}$, margin of error $(\alpha=0.05)$ and $95 \%$ confidence interval). $\mathrm{RSD}_{\mathrm{Rw}}$ values were below $3 \%$ in chicken eggs, egg powder, animal fat, fish, fish oil, poultry meat, whole milk, milk fat and milk powder and below $5 \%$ in bovine meat, bovine liver and infant food. These data correspond well to the results of a between-laboratory performance study evaluating Smedes' method [46] within the EU-Project QUASH [136] including mussel (2.3\% lipids, $\left.\mathrm{RSD}_{\mathrm{R}}=9 \%\right)$, plaice $\left(1.2 \%\right.$ lipids, $\left.\mathrm{RSD}_{\mathrm{R}}=10 \%\right)$ and herring $(10.3 \%$ lipids, $\mathrm{RSD}_{\mathrm{R}}=7 \%$ ).

With the exception of milk fat, the 95\% confidence intervals $(\mathrm{CI})$ of the mean extracted lipids obtained from MSE (this work) did not contain the mostly lower lipid results from Twisselmann extraction [65] of the same samples, indicating a significant difference between the

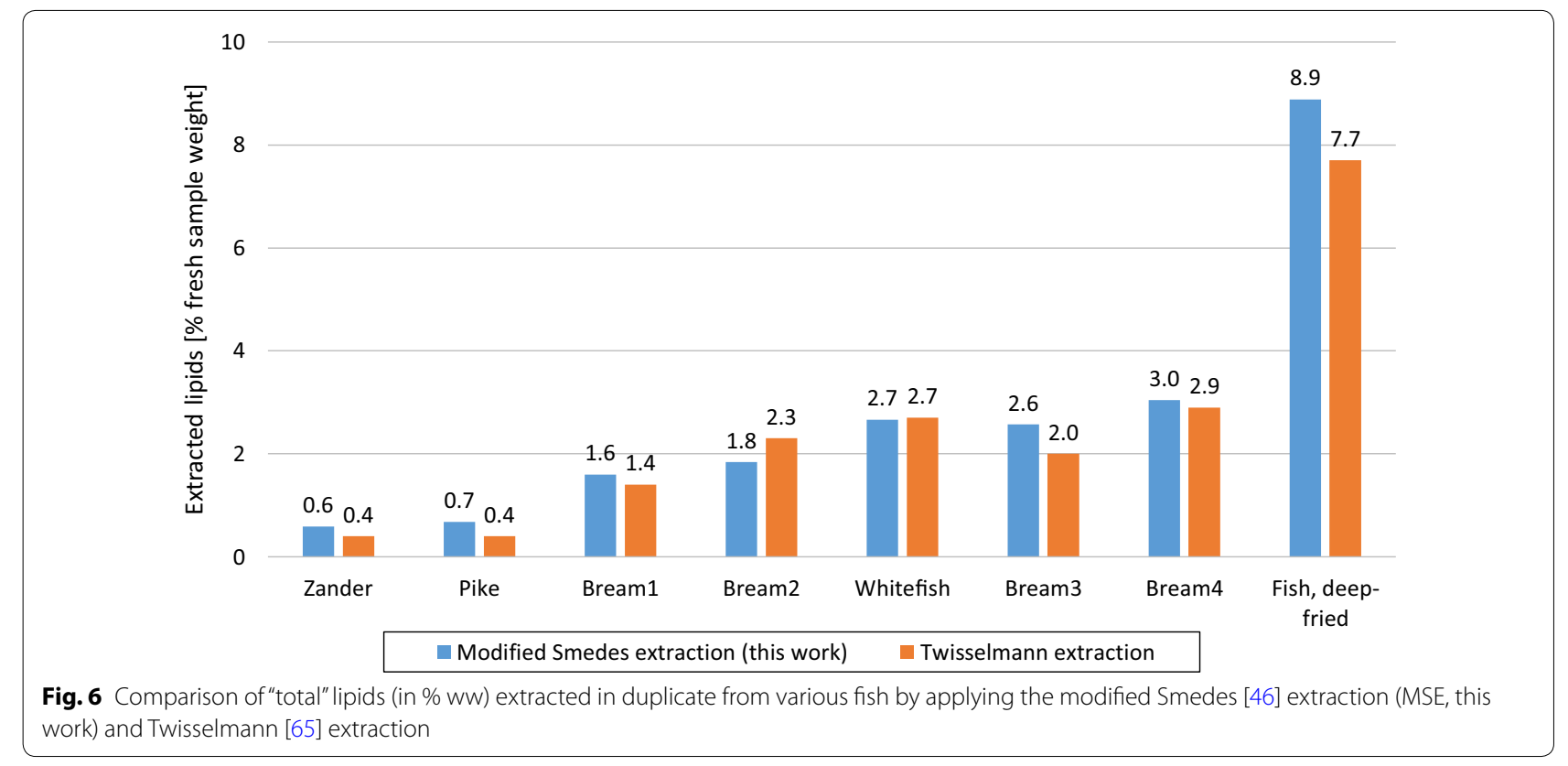




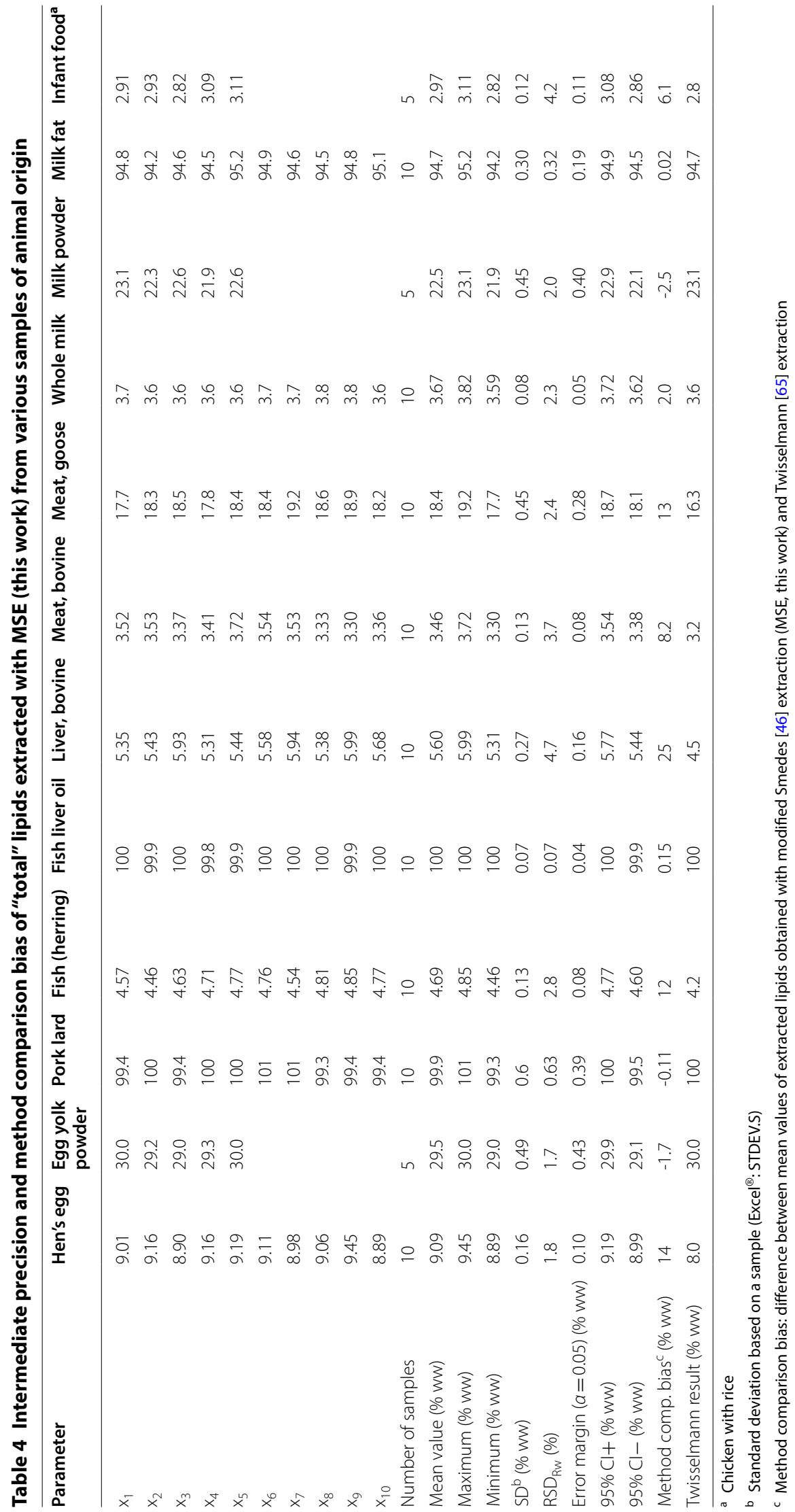


mean results of the two methods (Table 4). Following a general principle in method comparison, the difference between the mean values obtained with both methods represents a systematic deviation, the method comparison bias, of the candidate method (MSE, this work) compared to the recognized well-established Twisselmann extraction procedure. Notable method comparison bias values in total extracted lipids were $+13 \%$ ww in goose meat (mean $18.4 \%$ lipids), $+14 \%$ ww in chicken eggs (mean $9.1 \%$ lipids), $+12 \%$ ww in fish (mean $4.7 \%$ lipids), and $+25 \% \mathrm{ww}$ in liver (mean $5.6 \%$ lipids) (Table 4). This increase in lipid extraction efficiency translates more or less directly into a significant increase in wet weightbased analytical results measured for associated lipophilic POPs. Implications for assessment of compliance with legal limits within official food control are obvious samples previously (falsely) found contaminated below a maximum level (taking into account MU) from a less efficient extraction method are now more likely to be correctly identified as "non-compliant". Figure 7 depicts the closeness of agreement between "total" lipids (in \% ww) obtained from the modified Smedes extraction (MSE, this work) and from Twisselmann extraction for various EU-regulated food samples of animal origin.

\section{Method calibration}

We extracted "total" lipids under within-lab reproducibility conditions from 36 chicken egg samples, 31 bovine fat samples, 44 bovine liver samples, 36 fish meat samples, 50 bovine meat samples and 44 human whole milk samples. Human milk was chosen because contaminated cow's milk was not available. The cleaned-up extracts were analysed for the sum of dioxins and DL-PCBs. Each sample was submitted to Twisselmann (TW) hot extraction followed by GC/HRMS, and to modified Smedes extraction (MSE, this work) followed by CALUX bioassay analysis. The "total" lipids extracted by the two methods were plotted for all matrices on a log-log scale (Fig. 8) in order to achieve a better representation of the individual ranges. Especially for bovine liver and fish, to a lesser degree for bovine meat and chicken eggs, the majority of the data pairs (lipids TW/lipids MSE) were located above the line of agreement $(y=x)$. Linearity was observed across all tested sample types and across the full range of extracted lipids $(0.6-98 \%$ ww) with a high degree of correlation $\left(r^{2}=0.9912\right)$.

The bias of the respective centres of mass (CoM) calculated for each sample ("CoM, lipids TW" and "CoM, lipids MSE" in Table 5) agrees well with the method comparison bias values previously determined from individual samples of the same matrices (Table 4) suggesting a

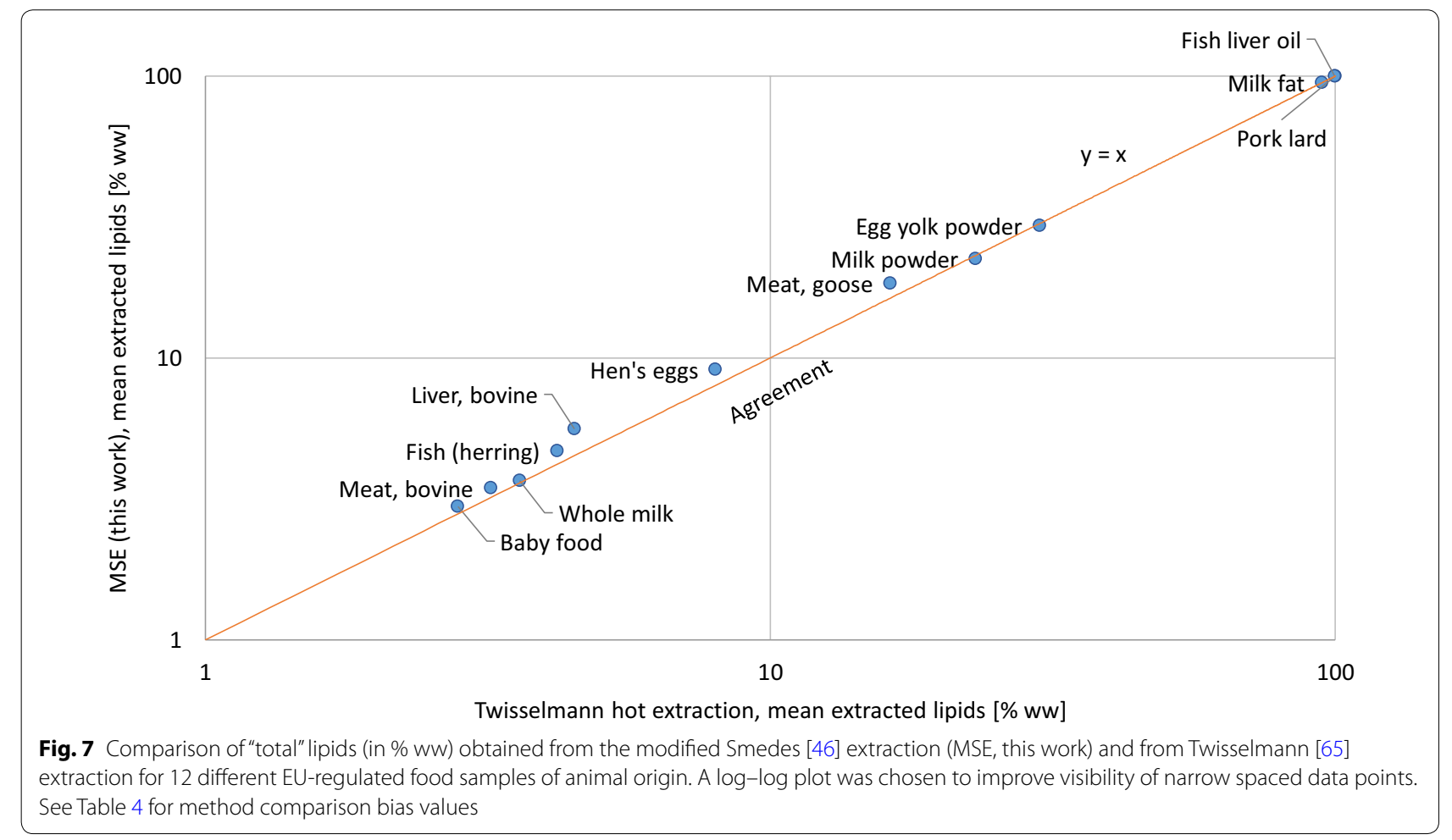




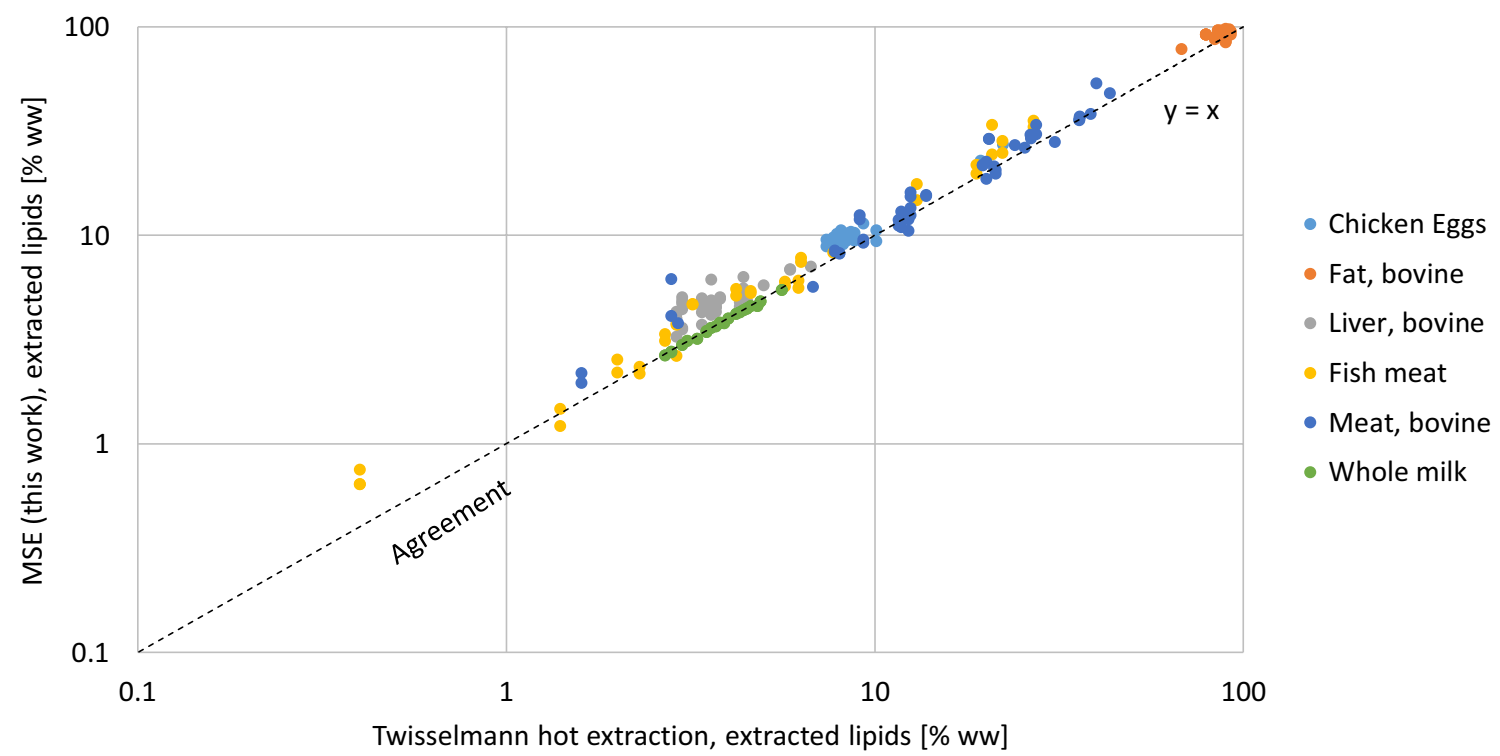

Fig. 8 Method calibration. "Total" extracted lipids (in \% ww) obtained from modified Smedes [46] extraction (MSE, this work) and from Twisselmann [65] hot extraction of chicken eggs, bovine fat, bovine liver, fish meat, bovine meat and (human) whole milk, each covering a range of lipid fractions. A log-log plot was chosen to improve visibility of narrow spaced data points

higher efficiency of the SME procedure presented in this paper.

For each sample, the sum of PCDD/Fs and DL-PCBs expressed as BEQs obtained from MSE (this work) and bioassay analysis, and WHO-PCDD/F-PCB-TEQs from Twisselmann extraction (TW) followed by GC/HRMS were plotted as TEQ/BEQ data pairs in Fig. 9a-f. BEQ and TEQ ranges analysed with both methods are given in Table 5 together with linear regression results and the limits of the $95 \%$-prediction interval $(\mathrm{PI} \pm$ ) calculated on the BEQ and TEQ values. These were highly correlated $\left(r^{2}=0.95-0.98\right)$ across each full concentration range. Calibration line slopes between 0.91 and 0.99 represent adequate method sensitivity while $y$-intercepts indicate low mean blank sample background values clearly below the respective calibration ranges. The relative residual standard deviation $\left(\mathrm{s}_{\mathrm{yx}, \mathrm{rel}}\right)$ was chosen to represent intermediate precision $\left(\mathrm{RSD}_{\mathrm{R}}\right)$ based on data variability within the calibrated range. Calculated at the respective centres of mass (CoM) to facilitate comparison between sample types, this dispersion parameter ranged from 9.3 to $13.8 \%$.

Particularly because correction of results for systematic errors using internal standards is not possible in bioanalysis, these parameters indicate a high level of performance and fully comply with the requirements laid down in Commission Regulation (EU) 2017/644 [2]. Chicken eggs, bovine fat, fish meat, bovine liver, meat and whole milk represent the main food sample types of animal origin. Within the scope of validation studies and for QC purposes, these matrices may be regarded representative for similar EU-regulated foods including samples from other farmed animals such as pigs and sheep, or from poultry, and products thereof.

\section{External quality control}

The MSE procedure (this work) was applied during a number of proficiency test studies involving $16 \mathrm{EU}$ regulated food samples and 4 feed samples, organized by RIKILT-Institute of Food Safety, Wageningen, NL, and by the PT unit of the EU-RL for Dioxins and PCBs in Feed and Food, Freiburg, DE. These studies were mandatory for National Reference Laboratories (NRLs) and Official Laboratories (OFLs) for dioxin and PCB analysis, while commercial laboratories usually could participate, as well. For sample types, assigned values, analytical results and z-scores for extracted lipids (where applicable) and for the sum of PCDD/Fs and DL-PCBs see Table 6 and Fig. 10. Assigned values were assessed as Huber's robust mean values [137] of those participants' results obtained from GC/HRMS or GC/MS-MS methods, after extreme outliers had been excluded. Fats, oils and plant materials did not involve assessment of lipid contents and therefore, no assigned values were calculated. Assuming a normal distribution of the results, performance of a laboratory 
Table 5 Method calibration

\begin{tabular}{|c|c|c|c|c|c|c|c|}
\hline Parameter & Unit & Chicken eggs & Fat, bovine & Liver, bovine & Fish meat & Meat, bovine & Whole milk \\
\hline Maximum level $[90,91]$ & $\mathrm{pg} T E Q / g$ & 5.0 & 4.0 & 0.50 & 6.5 & 4.0 & 5.5 \\
\hline Weight basis & & fat & fat & WW & WW & fat & fat \\
\hline Number of samples & & 36 & 31 & 44 & 36 & 50 & 44 \\
\hline Range, extracted lipids, TW & $\%$ WW & $7.4-22.3$ & $67.9-92.6$ & $2.9-6.7$ & $0.40-27.0$ & $1.6-43.5$ & $2.7-5.6$ \\
\hline Range, extracted lipids, MSE & $\%$ wW & $8.7-27.3$ & $78.8-98.0$ & $3.0-7.1$ & $0.64-35.4$ & $2.0-53.6$ & $2.7-5.5$ \\
\hline Centre of mass (CoM, lipids TW) & $\%$ wW & 9.3 & 86.3 & 3.8 & 8.2 & 17.9 & 3.9 \\
\hline Centre of mass (CoM, lipids MSE) & $\% \mathrm{WW}$ & 11.0 & 91.3 & 4.8 & 10.0 & 19.5 & 3.8 \\
\hline CALUX cell line used & & $\mathrm{H} 4 \mathrm{~L} 7.5 \mathrm{c} 2 \mathrm{rat}$ & H1L6.1c3 mouse & H4L7.5c2 rat & H4L7.5c2 rat & $\mathrm{H} 4 \mathrm{~L} 7.5 \mathrm{c} 2 \mathrm{rat}$ & H1L6.1c3 mouse \\
\hline Range, TEQ concentrations & $\mathrm{pg} T E Q / g$ & $0.57-9.23$ & $0.91-12.7$ & $0.076-1.19$ & $0.55-8.01$ & $0.30-8.24$ & $0.53-14.0$ \\
\hline Range, BEQ concentrations & $\mathrm{pg} \mathrm{BEQ/g}$ & $0.45-9.40$ & $0.69-11.5$ & $0.100-1.27$ & $0.51-8.19$ & $0.49-7.64$ & $0.38-13.8$ \\
\hline Centre of mass (CoM, TEQ) & $\mathrm{pg} \mathrm{TEQ} / \mathrm{g}$ & 3.53 & 4.64 & 0.416 & 2.64 & 3.30 & 6.63 \\
\hline Centre of mass (CoM, BEQ) & $\mathrm{pg} B E Q / g$ & 3.68 & 4.79 & 0.426 & 2.78 & 2.99 & 6.31 \\
\hline Correlation coefficient $(r)$ & & 0.9911 & 0.9801 & 0.9830 & 0.9850 & 0.9841 & 0.9744 \\
\hline $\begin{array}{l}\text { Critical value for } r(d f=n-2, p=0.05 \text {, } \\
\text { two-sided })\end{array}$ & & 0.3291 & 0.3550 & 0.2973 & 0.3291 & 0.2787 & 0.2973 \\
\hline Square correlation coefficient $\left(r^{2}\right)$ & & 0.9822 & 0.9606 & 0.9663 & 0.9702 & 0.9685 & 0.9495 \\
\hline Slope (sensitivity) & & 0.979 & 0.950 & 0.925 & 0.989 & 0.920 & 0.912 \\
\hline Standard error of the slope & & 0.023 & 0.036 & 0.027 & 0.030 & 0.024 & 0.031 \\
\hline y-Intercept (mean blank signal) & $\mathrm{pg} \mathrm{BEQ/g}$ & 0.224 & 0.379 & 0.041 & 0.16 & -0.04 & 0.27 \\
\hline Standard error of the $y$-intercept & $\mathrm{pg} B E Q / g$ & 0.098 & 0.197 & 0.013 & 0.101 & 0.090 & 0.228 \\
\hline Residual standard deviation $\left(\mathrm{s}_{\mathrm{yx}}\right)$ & $\mathrm{pg} B E Q / g$ & 0.34 & 0.59 & 0.047 & 0.38 & 0.31 & 0.69 \\
\hline Relative residual SD $\left(s_{y x, \text { rel }}\right)$ at $\operatorname{CoM}^{a}$ & $\%$ & 9.3 & 12.3 & 10.9 & 13.8 & 10.2 & 10.9 \\
\hline Error margin at $\operatorname{CoM}(a=0.05)$ & $\mathrm{pg} \mathrm{BEQ/g}$ & 0.95 & 1.65 & 0.128 & 1.06 & 0.83 & 1.87 \\
\hline 95\% Prediction interval $(\mathrm{PI}+)$ at CoM & $\mathrm{pg} \mathrm{BEQ/g}$ & 4.62 & 6.44 & 0.554 & 3.84 & 3.82 & 8.18 \\
\hline 95\% Prediction interval (PI-) at CoM & $\mathrm{pg} B E Q / g$ & 2.73 & 3.14 & 0.299 & 1.72 & 2.17 & 4.45 \\
\hline
\end{tabular}

Regression on results (dioxins and DL-PCBs) from the modified Smedes [46] extraction (MSE, this work) followed by CALUX bioassay analysis, and from Twisselmann [65] extraction (TW) followed by GC/HRMS analysis, of chicken eggs, bovine fat, bovine liver, fish meat, bovine meat and (human) whole milk

a Instead of $\mathrm{RSD}_{\mathrm{R}}$, the relative residual standard deviation ( $\left.s_{\mathrm{yx}, \mathrm{re}}\right)$ at CoM was calculated to assess variability of MSE/bioanalytical results based on the calibrated range.

is considered satisfactory if a participant's z-score lies in a range between -2 and +2 . $Z$-scores between -0.9 and 1.1 for "total" extracted lipids and between -0.5 and 1.2 for the sum of PCDD/Fs and DL-PCBs demonstrate beyond successful validation performed according to Commission Regulation (EU) 2017/644 [2] that the modified Smedes [46] extraction (MSE) presented in this paper is suitable for its intended purpose.

\section{Conclusions}

European Union food law requires a wide range of food samples to be regularly analysed for elevated levels of lipophilic POPs by the competent official laboratories of the EU Member States to support regulatory compliance, investigation and enforcement actions. We present a fast and efficient routine method that for the first time enables the analyst to extract "total" lipids from any sample of animal origin for which the EU has set maximum levels for lipophilic POPs such as dioxins, furans and dioxin-like PCBs. Smedes' 3-step procedure developed for marine tissues [46] was extended to chicken eggs, egg yolk powder, animal fat, fish meat, fish liver oil, bovine liver, bovine meat, poultry meat, whole milk, milk powder, milk fat and infant food. The resulting modified Smedes extraction (MSE) was optimized based on these matrices as proxies for other sample types, in terms of solvent composition, extraction efficiency for lipids and lipophilic pollutants and quick phase separation, while the time-consuming centrifugation step was abandoned.

The water fraction in Smedes' propan2-ol:cyclohexane:water mixture $(8: 10: 11, \mathrm{v} / \mathrm{v} / \mathrm{v})$, was increased for milk extraction to $8: 10: 12(\mathrm{v} / \mathrm{v} / \mathrm{v})$. For extraction of all other matrices, we reduced the water proportion to 8:10:8 $(\mathrm{v} / \mathrm{v} / \mathrm{v})$, and to $8: 10: 6(\mathrm{v} / \mathrm{v} / \mathrm{v})$ for fats and oils. At the same time, the propan-2-ol:water ratio was changed from 8:11 (v/v) to $1: 1(\mathrm{v} / \mathrm{v})$ or even to $4: 3$ $(\mathrm{v} / \mathrm{v})$ for fats and oils. This may well explain an increase in extracted lipids from fish and liver compared to results from Twisselmann [65] extraction, propan-2-ol being a suitable solvent for phospholipids which make up a considerable proportion of the total lipids in both matrices. We also increased the ratio of cyclohexane to the fresh 


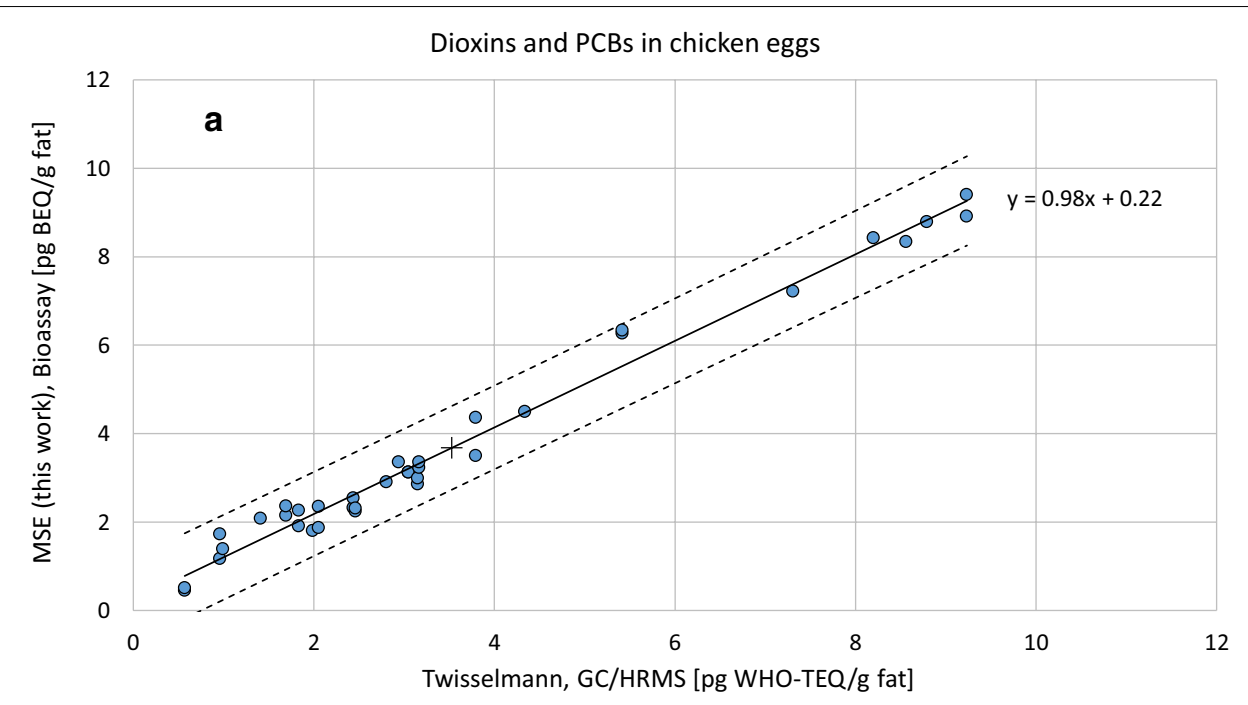

Dioxins and PCBs in bovine fat

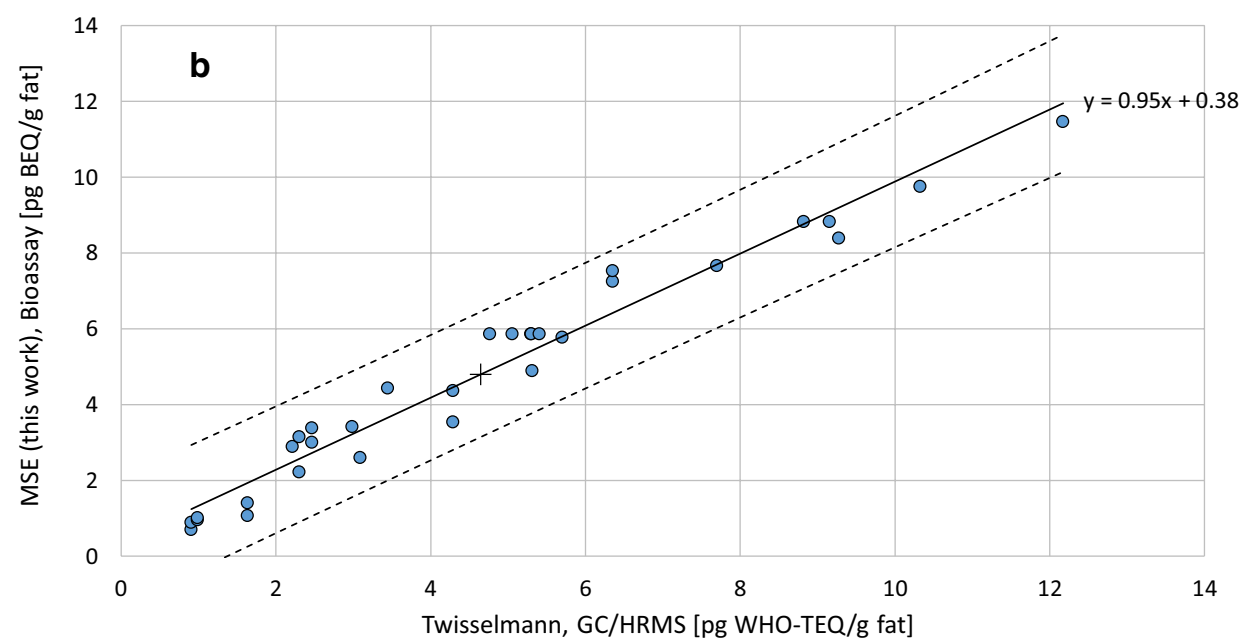

Dioxins and PCBs in bovine liver

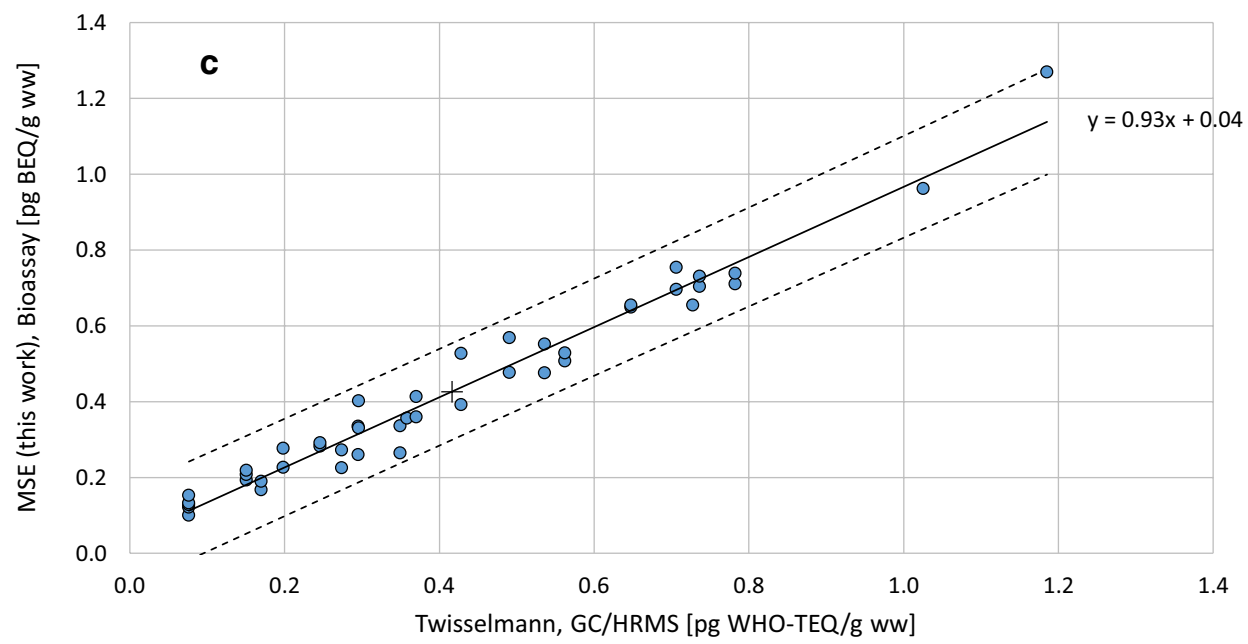

Fig. 9 Method calibration: dioxins and PCBs in a chicken eggs, b bovine fat, $\mathbf{c}$ bovine liver, $\mathbf{d}$ fish meat, e bovine meat and $\mathbf{f}$ (human) whole milk. Results from modified Smedes [46] extraction (MSE, this work) followed by CALUX bioassay analysis (pg BEQ/g fat, or ww), and from Twisselmann [65] extraction followed by GC/HRMS (pg WHO-TEQ/g fat, or ww); - regression line, -- 95\% prediction intervals, + centre of mass 

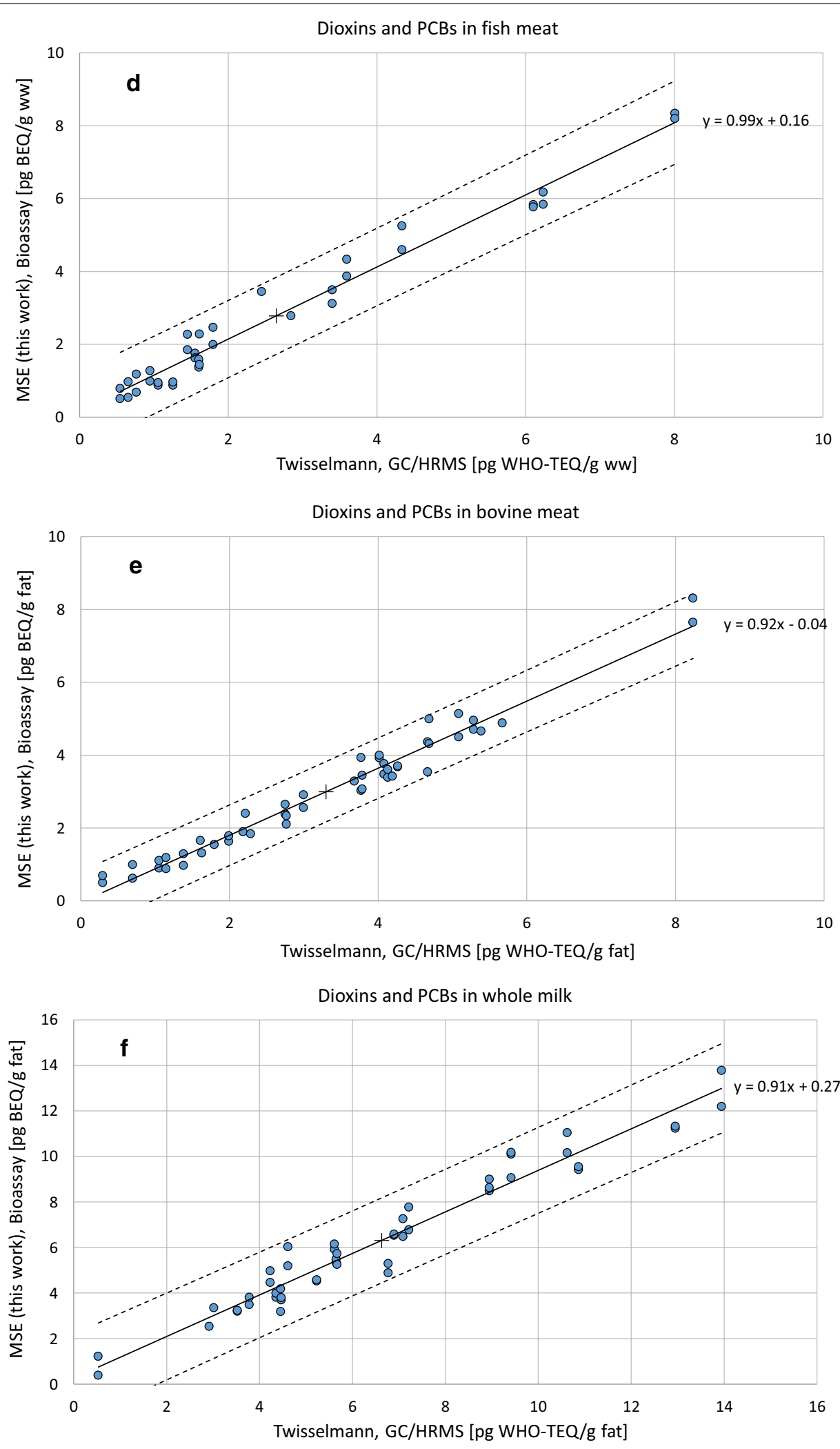

Fig. 9 continued 


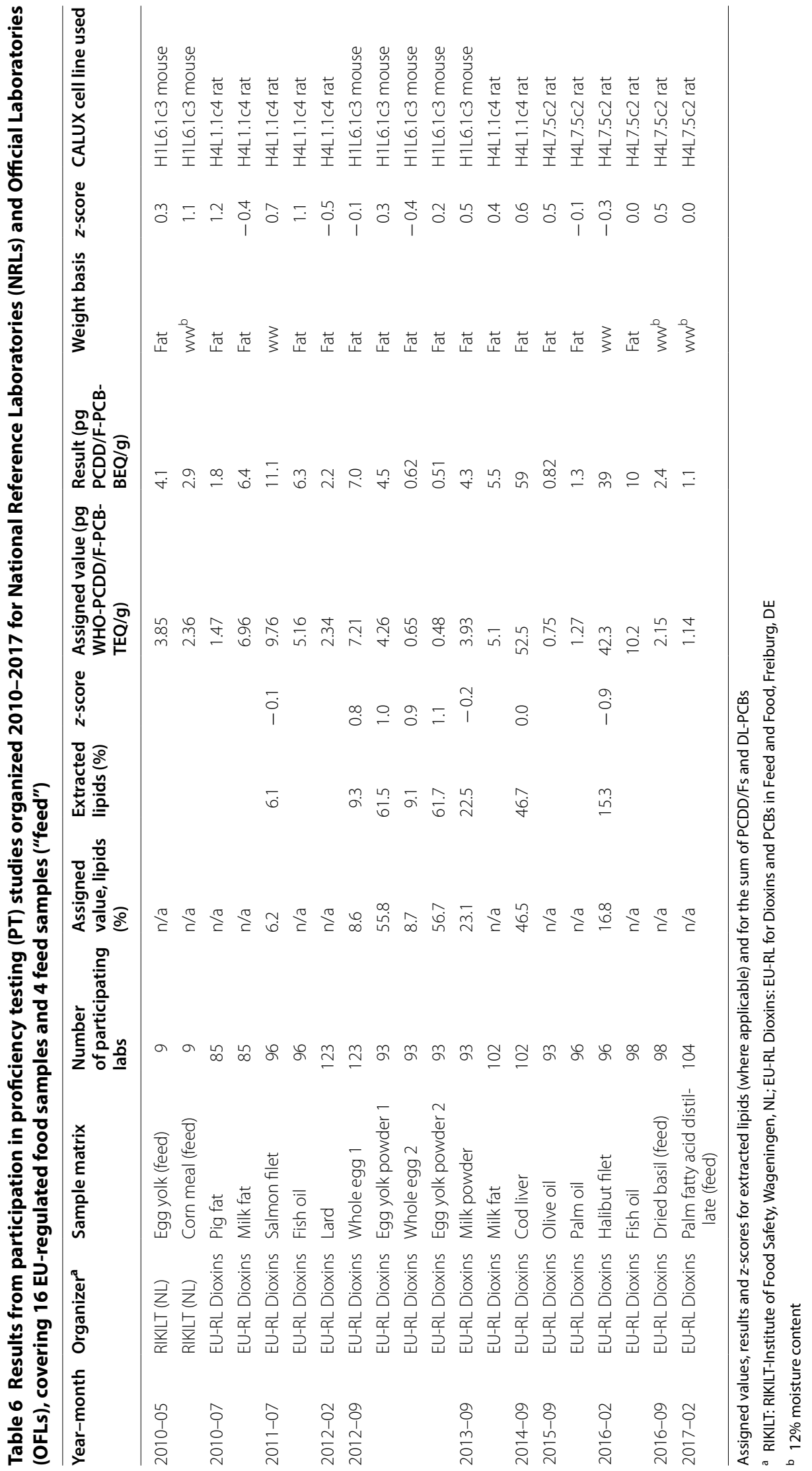




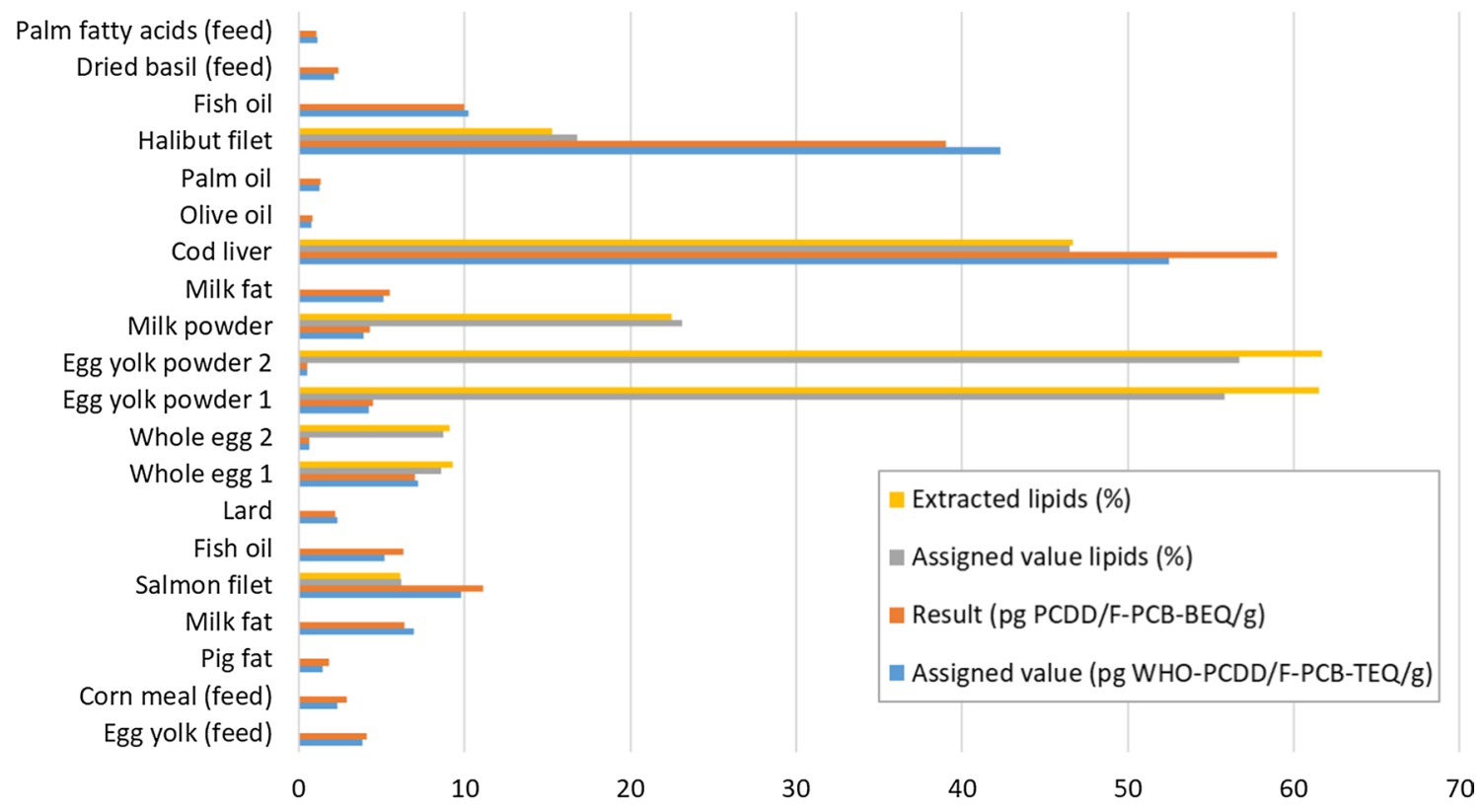

Extracted lipids [\%], or concentration [pg PCDD/F-PCB-BEQ/g or pg WHO-PCDD/F-PCB-TEQ/g]

Fig. 10 Results from participation in proficiency testing (PT) studies organized 2010-2017 for National Reference Laboratories (NRLs) and Official Laboratories (OFLs), covering 16 EU-regulated food samples and 4 feed samples ("feed"). Assigned values and results for extracted lipids (where applicable) and for the sum of PCDD/Fs and DL-PCBs (for numerical values see Table 6)

sample mass from 2:1 (v/w, Smedes) to 4:1 (v/w), except for milk $(4: 3, \mathrm{v} / \mathrm{w})$, infant food $(2: 1, \mathrm{v} / \mathrm{w})$, and fats and oils $(40: 1, \mathrm{v} / \mathrm{w})$. The resulting low lipid concentrations did not exceed $0.65 \mathrm{~g}$ per $10 \mathrm{~mL}$ cyclohexane in the extraction of milk powder and $0.3 \mathrm{~g}$ per $10 \mathrm{~mL}$ cyclohexane in all other matrices, hardly affecting the nature and extraction properties of the organic phase and thus not reducing the extraction efficiency.

Through briefly homogenizing the ternary solventmatrix mixture with an Ultra-Turrax ${ }^{\circledR}$ device, a range of solvent polarities is readily available for release of lipids and associated lipophilic POPs combined with the crushing force of the high performance dispenser. Phase separation is spontaneous and complete within 15-30 s in all matrices except in fish and liver. These tend to form emulsions requiring few extra $\mathrm{mL}$ of propan-2-ol to be added and three (instead of two) repetitions of the extraction to be performed if the recovery of the cyclohexane volume separated on top was below 25\%. Partitioning is complete within a few seconds by removing the upper organic phase with an automated pipette controller equipped with a glass pipette.

Intermediate precision of extracted lipids as one key performance indicator assessed by multiple analysis of 12 different food samples was below 3\% in chicken eggs, egg powder, animal fat, fish, fish oil, poultry meat, whole milk, milk fat and milk powder and below $5 \%$ in bovine meat, bovine liver and infant food. In comparison to the Twisselmann extraction efficiency, the method comparison showed significant bias values of $+25 \%$ for bovine liver, $+14 \%$ for chicken eggs, $+13 \%$ for goose meat, $+12 \%$ for fish muscle, $8.2 \%$ for bovine meat and $6.1 \%$ for infant food. These data were confirmed in principle by calibrating the results obtained by MSE (this work) with those obtained by Twisselmann hot extraction of numerous samples involving 6 key matrices. The observed increase in lipid extraction efficiency translates more or less directly into a significant increase in wet weight-based analytical results measured for associated lipophilic POPs. This is of special interest in the case of wet weight-based fish and liver results. Samples previously (falsely) found contaminated below a maximum level (taking into account MU) from less efficient extraction methods are now more likely to be correctly identified as "non-compliant". These data show that, whether analytical results are expressed on wet weight or on lipid basis, MSE provides a more complete, reproducible extraction of both the lipids and the lipophilic analytes of interest from foods of animal origin.

The described MSE procedure was validated with regard to efficiency, extract purity, intermediate precision, method comparison bias, calibration, dynamic range, linearity, sensitivity, and performance in proficiency testing. It also constitutes an important step 
in a highly sensitive ultra-trace bioanalytical method for dioxin and PCB analysis, fully validated [104-106] according to the high level requirements of Commission Regulation (EU) 2017/644 [2]. The assay does not allow for internal standard correction of the results and is very sensitive to interference from accompanying compounds that are cytotoxic to the bioassay cell system and/ or structurally related to the target analytes thus altering the overall cell response. The short dispersion times applied seem to reduce extraction efficiency for such unwanted chemicals allowing a straight-forward clean-up procedure and being of considerable significance for the selectivity of the assay. Performance parameters achieved from our validation studies not only demonstrate the suitability of the CALUX cell bioassay within official food control, but based on the feedback we have received from various NRLs, our protocol is also suitable for HRMSbased confirmatory analysis.

In addition to the CALUX bioassays, numerous other cell-based bioassays have been developed, optimized and successfully utilized for the detection and relative quantitation of TCDD and related halogenated aromatic hydrocarbons in a wide variety of matrices (reviewed in [112, 138-141]). Measurement of the induction of ethoxyresorufin O-deethylase (EROD), an enzymatic activity associated with the AhR-responsive gene cytochrome P4501A1 (CYP1a1), was an early AhR-based cell bioassay with relatively widespread use [139]. A significantly improved version of the EROD bioassay (micro-EROD) has been described and used extensively for environmental samples [140-142] and this assay is also in accordance with Commission Regulation (EU) 2017/644 [2]. Given the success obtained with the MSE method and subsequent analysis by CALUX, this procedure would also be expected to be suitable for sample analysis using other AhR-based bioassay methods. However, experimental validation of the utility of the MSE method is necessary for each AhR bioassay given significant differences between many of the protocols and cells of other bioassays and those of CALUX.

The analyst is able to extract a fish or liver sample within $8 \mathrm{~min}$ and all other sample types of animal origin within 6 min. A series of 12 samples can be processed from weigh-in to the dried extract within $3 \mathrm{~h}$ for fish and liver and within $2.5 \mathrm{~h}$ for all other matrices. Compared to a $4 \mathrm{~h}$ Twisselmann hot extraction, the time saving for the extraction of 1000 samples annually is $252 \mathrm{~h}$ or 32 working days per year if 2 series of 12 samples are processed each week. The advantage of such accelerated and versatile methods for lipid extraction followed by POPs analysis is economically obvious in routine analysis and during so-called "contamination incidents", when large numbers of samples must be analysed within very short time periods in order to enable detection of sources and paths of contamination as quickly as possible.

In summary, the modified Smedes extraction (MSE) method presented is suitable for "total" lipid extraction from a large variety of food samples of animal origin and for use in ultra-trace analysis of lipid-associated POPs in the context of official food control. MSE significantly contributes to the harmonization of analytical results generated by screening and confirmatory methods applied according to the requirements laid down in Commission Regulation (EU) 2017/644 [2].

\section{Abbreviations}

AhR: Aryl hydrocarbon receptor; $A$ L: Action level; $\mathrm{AL}_{\text {fat }}$ : Action level, based on fat; $\mathrm{AL}_{w w}$ : Action level, based on wet weight; ASE: Accelerated solvent extraction; BEQ: Bioanalytical equivalent; BfR: Federal Institute for Risk Assessment (Germany); CALUX: Chemically Activated LUciferase gene eXpression; $\mathrm{Cl}+$ : Confidence interval, upper limit; Cl-: Confidence interval, lower limit; CoM: Centre of mass; CONTAM: EFSA's Panel on Contaminants in the Food Chain; CV: Coefficient of variation; CVUA: Chemisches und Veterinaeruntersuchungsamt (Chemical and Veterinary Inspection Office); DDD: Dichlorodiphenyldichloroethane, 1,1'-(2,2-dichloroethane-1,1-diyl)bis(4-chlorobenzene); DDE: Dichlorodiphenyldichloroethylene, 1,1'-(2,2-dichloroethene-1,1-diyl) bis(4-chlorobenzene); dd $\mathrm{H}_{2} \mathrm{O}$ : Double-distilled water; DDT: Dichlorodiphenyltrichloroethane, 1-chloro-4-[2,2,2-trichloro-1-(4-chlorophenyl)ethyl]benzene; DL-PCB: Dioxin-like polychlorinated biphenyl; DNA: Deoxyribonucleic acid; DRE: Dioxin responsive element; EFSA: European Food Safety Authority; EROD: Ethoxyresorufin O-deethylase; EU-RL: European Union Reference Laboratory; GC: Gas chromatography; HCB: Hexachlorobenzene; HCH: Hexachlorocyclohexane; HRMS: High-resolution mass spectrometry; IEC: International Electrotechnical Commission; IS: Internal standard; ISO: International Organization for Standardization; IUPAC: International Union of Pure and Applied Chemistry; LOQ: Limit of quantification; MFGM: Milk fat globule membrane; ML: Maximum level; $\mathrm{ML}_{\mathrm{fat}}$ : Maximum level, based on fat; $\mathrm{ML}_{\mathrm{ww}}$ : Maximum level, based on wet weight; MPa: Megapascal; MRL: Maximum residue level; MSE: Modified Smedes extraction (this work); MTBE: Methyl tert-butyl ether, 2-methoxy-2-methylpropane; MU: Measurement uncertainty; NDL-PCB: Nondioxin-like polychlorinated biphenyl; NRL: National Reference Laboratory; OCP: Organochlorine pesticide; OFL: Official Laboratory; PAH: Polycyclic aromatic hydrocarbon; PCDD: Polychlorinated dibenzo-p-dioxin; PCDF: Polychlorinated dibenzofuran; PI+: Prediction interval, upper limit; PI-: Prediction interval, lower limit; 4PL: 4-Parameter logistic (function); PLE: Pressurized liquid extraction; POP: Persistent organic pollutant; PT: Proficiency testing; QC: Quality control; REP: Relative potency (relative response of the CALUX cell system); RLU: Relative light units; $\mathrm{RSD}_{\mathrm{R}}$ : Relative standard deviation, between-laboratory reproducibility conditions; $\mathrm{RSD}_{\mathrm{Rw}}$ : Relative standard deviation, within-laboratory reproducibility conditions; SAP: Super absorbent polymer; SCF: Scientific Committee on Food; SD: Standard deviation; $\mathrm{SCO}_{2}$ : Supercritical carbon dioxide; SCOFCAH: Standing Committee on the Food Chain and Animal Health; SFE: Supercritical fluid extraction; TCDD: 2,3,7,8-Tetrachlorodibenzo-p-dioxin; TEQ: Toxic equivalent; U: Expanded measurement uncertainty; UNEP: United Nations Environment Programme; WHO: World Health Organization; ww: Wet weight (also termed fresh weight, product weight, whole weight.

\section{Acknowledgements}

The authors wish to thank CVUA Freiburg's physico-chemical routine lab for dioxin analysis for making available most of the samples used in this study together with results from determination of the extractable lipid content and from GC/HRMS analysis.

\section{Authors' contributions}

$\mathrm{JH}$ as head of the Bioanalytical Research Lab at the EU-RL for Dioxins and PCBs in Feed and Food is responsible for the general design, method optimization studies, strategies for validation and quality control, statistical evaluation of 
results and drafting the manuscript. CS optimized and performed lipid extraction, clean-up of extracts, bioanalytical measurement, raw data processing, calibration and validation experiments. MSD is inventor of the recombinant mouse and rat hepatoma cell lines containing stably integrated AhR-responsive luciferase reporter gene plasmid as detection system, supervisor of the project and critically revised the manuscript. All authors read and approved the final manuscript.

\section{Funding}

We gratefully acknowledge the European Commission's financial support of the work of the Bioassay Research Laboratory at the European Union Reference Laboratory for Dioxins and PCBs in Feed and Food (EU-RL), Freiburg (Germany) and support from a Superfund Research Grant (P42ES004699) from the National Institute for Environmental Health Sciences (US).

\section{Availability of data and materials}

The datasets used and/or analysed during the current study are available from the corresponding author on reasonable request.

\section{Ethics approval and consent to participate}

Not applicable.

\section{Consent for publication}

Not applicable.

\section{Competing interests}

The authors declare that they have no competing interests.

\section{Author details}

${ }^{1}$ European Union Reference Laboratory (EU-RL) for Dioxins and PCBs in Feed and Food, CVUA Freiburg, Bissierstraße 5, 79114 Freiburg, Germany. ${ }^{2}$ Department of Environmental Toxicology, University of California Davis (UCD), One Shields Avenue, Davis, CA 95616, USA. ${ }^{3}$ Ringstr. 5, 79252 Stegen, Germany.

Received: 26 May 2020 Accepted: 3 September 2020

Published online: 18 September 2020

\section{References}

1. Becker L, Hennecke D, Düring R-A (2011) Assessment of exposure and transfer of Dioxins, dioxin-like PCBs and PCBs - Literature review. Fraunhofer Institute for Molecular Biology and Applied Ecology, and Justus-Liebig-University Giessen.

2. Commission Regulation (EU) $2017 / 644$ of 5 April 2017 laying down methods of sampling and analysis for the control of levels of dioxins, dioxin-like PCBs and non-dioxin-like PCBs in certain foodstuffs and repealing Regulation (EU) No 589/2014, OJ L 92, 06.04.2017, p. 9-34.

3. Fahy E, Cotter D, Sud M (1811) Subramaniam S (2011) Lipid classification, structures and tools. Biochim Biophys Acta 11:637-647

4. Kikas P, Chalikias G, Tziakas D (2018) Cardiovascular implications of sphingomyelin presence in biological membranes. Eur Cardiol 13(1):42-45

5. Martin S, Parton RG (2006) Lipid droplets: a unified view of a dynamic organelle. Nat Rev Mol Cell Biol 7:373-378

6. Lovern JA (1953) The Lipids of Fish, 1. Content and condition of lipids in the flesh of the haddock (Gadus aeglefinus). Biochem J 54:126-128

7. Berenbaum MC (1958) The histochemistry of bound lipids. Q J MicrosC Sci 99(2):231-242

8. Christie WW (1981) Lipid metabolism in ruminant animals. Pergamon Press, Oxford

9. Mourot J, Hermier D (2001) Lipids in monogastric animal meat. Reprod Nutr Dev EDP Sci 41(2):109-118

10. Pikul J, Leszczynski DE, Kummerow FA (1985) Total lipids, fat composition, and malonaldehyde concentration in chicken liver, heart, adipose tissue, and plasma. Poult Sci J 64(3):469-475

11. Stadelman WJ, Cotterill OJ (1995) Egg Science and Technology, 4th edn. The Haworth Press, New York, pp 115-119

12. Kuang H, Yang F, Zhang Y, Wang T, Chen G (2018) The impact of egg nutrient composition and its consumption on cholesterol homeostasis. Cholesterol 2018:1-22
13. Dewettinck K, Rombaut R, Thienpont N, Le TT, Messens K, Van Camp J (2008) Nutritional and technological aspects of milk fat globule membrane material. Int Dairy J 18(5):436-457

14. Gunstone FD, Harwood JL, Padley FB (1994) The Lipid Handbook, 2nd edn. Chapman \& Hall, London

15. Kailasapathy K (2008) Chemical composition, physical and functional properties of milk and milk ingredients. In: Chandan RC, Kilara A, Shah N (eds) Dairy processing and quality assurance. Wiley-Blackwell, New York, pp 75-103

16. Sheridan MA (1988) Lipid dynamics in fish: aspects of absorption, transportation, deposition and mobilization. Comp Biochem Physiol B Biochem Mol Biol 90(4):679-690

17. Sirot V, Oseredczuk M, Bemrah-Aouachria N, Volatier J-L, Leblanc J-C (2008) Lipid and fatty acid composition of fish and seafood consumed in France: CALIPSO study. J Food Compos Anal 21(1):8-16

18. Takama K, Suzuki T, Yoshida K, Arai H, Anma H (1994) Lipid content and fatty acid composition of phospholipids in white-flesh fish species. Fisheries Sci 60(2):177-184

19. Walker CH, Sibly R, Hopkin SP, Peakall D (2001) Principles of ecotoxicology, 2nd edn. CRC Press, London

20. Yu GW, Laseter J, Mylander C (2011) Persistent organic pollutants in serum and several different fat compartments in humans. J Environ Public Health 2011(4):417980. https://doi.org/10.1155/2011/417980

21. Covaci A, Gheorghe A, Schepens P (2004) Distribution of organochlorine pesticides, polychlorinated biphenyls and $\mathrm{a}-\mathrm{HCH}$ enantiomers in pork tissues. Chemosphere 56(8):757-766

22. Schulz AJ, Wiesmüller T, Appuhn H, Stehr D, Severin K, Landmann D, Kamphues J (2005) J Anim Physiol Anim Nutr 89:72-78

23. Lund KH, Sørensen S, Cederberg TL (2008) PCDD/F and PCB content in different parts of sheep. Organohalogen Compd 70:1724

24. Wahl K, Malisch R, Kotz A, Djuchin K, Haedrich J (2013) Levels of PCDD/ Fs and PCBs in meat and liver of different animal species and comparison with regulatory limits. Organohalogen Compd 75:1024-1027

25. Adamse P, Schoss S, Theelen RMC, Hoogenboom RLAP (2017) Levels of dioxins and dioxin-like PCBs in food of animal origin in the Netherlands during the period 2001-2011. Food Add Contam Part A 34(1):78-92. https://doi.org/10.1080/19440049.2016.1252065

26. EFSA Panel on Contaminants in the Food Chain (CONTAM) (2018) Scientific Opinion on the risk for animal and human health related to the presence of dioxins and dioxin-like PCBs in feed and food. EFSA J 16(11):5333. https://doi.org/10.2903/j.efsa.2018.5333

27. Shen $\mathrm{H}$, Henkelmann B, Rambeck WA, Mayer R, Wehr U, Schramm KW (2012) Physiologically based persistent organic pollutant accumulation in pig tissues and their edible safety differences: an in vivo study. Food Chem 132(4):1830-1835. https://doi.org/10.1016/j.foodc hem.2011.12.015

28. Jandacek RJ, Anderson N, Liu M, Zheng S, Yang Q, Tso P (2005) Effects of yo-yo diet, caloric restriction, and olestra on tissue distribution of hexachlorobenzene. Am J Physiol Gastrointest Liver Physiol 288:G292-G299

29. Lee Y-M, Kim K-S, Jacobs DR Jr, Lee D-H (2017) Persistent organic pollutants in adipose tissue should be considered in obesity research. Obes Rev 18(2):129-139. https://doi.org/10.1111/obr.12481

30. Wu W-Z (1999) Environmental Behavior and Ecotoxicological Impact of Persistent Organic Pollutants (POP) in wildlife, with special emphasis on the aquatic ecosystem. Herbert Utz Verlag, München

31. Chefurka W, Gnidec EPP (1987) Binding of [14C] DDT by submitochondrial particles. Comp Biochem Physiol C 88(1):213-217

32. Randall RC, Young DR, Lee H II, Echols SF (1998) Lipid methodology and pollutant normalization relationships for neutral nonpolar organic pollutants. Environ Toxicol Chem 17(5):788-791

33. De Boer J (1988) Chlorobiphenyls in bound and non-bound lipids of fishes; comparison of different extraction methods. Chemosphere 17(9):1803-1810

34. Brázová T, Hanzelová V, Šalamún P (2015) Ecological risk and distribution of polychlorinated biphenyls in fish. In: Larramendy ML, Soloneski $S$ (ed) Emerging Pollutants in the Environment-Current and Further Implications. IntechOpen. https://doi.org/10.5772/60405.

35. Kampire E, Rubidge G, Adams JB (2015) Distribution of polychlorinated biphenyl residues in several tissues of fish from the North End Lake, Port Elizabeth. South Africa Water SA 41(4):559-570. https://doi. org/10.4314/wsa.v41i4.16 
36. Christie WW (1993) Preparation of lipid extracts tissues. In: Christie WW (ed) Advances in lipid methodology, vol 2. The Oily Press, Dundee, pp 195-213

37. Bergeron F, Benning M: Comparison of Two Fat Extraction Methods. https://web2.slc.qc.ca/jmc/www/Chemweb/oldchemweb/extraction methods.htm. Accessed 15 March 2020

38. Schlechtriem C, Fliedner A, Schäfers C (2009) Contributions to the Revision of TG OECD 305-Lipid measurement. Fraunhofer Institute for Molecular Biology and Applied Ecology

39. Folch J, Lees M, Stanley GHS (1957) A simple method for the isolation and purification of total lipids from animal tissues. J Biol Chem 226:497-509

40. Schmid P (1973) Extraction and purification of lipids. II. Why is chloroform-methanol such a good lipid solvent. Physiol Chem Phys 5:141-150

41. Castro-Gómez MP, Rodriguez-Alcalá LM, Calvo MV, Romero J, Mendiola JA, Ibañez E, Fontecha J (2014) Total milk fat extraction and quantification of polar and neutral lipids of cow, goat, and ewe milk by using a pressurized liquid system and chromatographic techniques. J Dairy Sci 97:6719-6728

42. Bligh EG, Dyer WJ (1959) A rapid method of total lipid extraction and purification. Can J Biochem Physiol 37:911

43. Carlson LA (1985) Extraction of lipids from human whole serum and lipoproteins and from rat liver tissue with methylene chloride-methanol: a comparison with extraction with chloroform-methanol. Clin Chim Acta 149:89-93

44. Hara A, Radin NS (1978) Lipid extraction of tissues with low-toxicity solvent. Anal Biochem 90:420-426

45. Furusawa N, Ozaki A, Nakamura M, Morita Y, Okazaki K (1999) Simple and rapid extraction method of total egg lipids for determining organochlorine pesticides in the egg. J Chromatogr A 830(2):473-476

46. Smedes $F(1999)$ Determination of total lipid using non-chlorinated solvents. Analyst 124:1711-1718

47. UNEP (1987) The Montreal Protocol on Substances that Deplete the Ozone Layer (Montreal Protocol). United Nations Environment Programme.

48. Jensen S, Häggberg L, Jörundsdóttir H, Odham G (2003) A quantitative lipid extraction method for residue analysis of fish involving nonhalogenated solvents. J Agric Food Chem 51:5607-5611

49. Löfgren L, Forsberg G-B, Ståhlman M (2016) The BUME method: a new rapid and simple chloroform-free method for total lipid extraction of animal tissue. Sci Rep 6:27688. https://doi.org/10.1038/srep27688

50. Cruz M, Wang M, Frisch-Daiello J, Han X (2016) Improved ButanolMethanol (BUME) method by replacing acetic acid for lipid extraction of biological samples. Lipids 51:887-896. https://doi.org/10.1007/s1174 5-016-4164-7

51. Sturm J, Wienhold P, Frenzel T, Speer K (2018) Ultra turrax ${ }^{\circledR}$ tube drive for the extraction of pesticides from egg and milk samples. Anal Bioanal Chem 410:5431-5438

52. Anastassiades M, Lehotay SJ, Stajhbaher D, Schenk FJ (2003) Fast and easy multi residue method employing acetonitrile extraction/partitioning and "dispersive solid-phase extraction" for the determination of pesticide residues in produce. J AOAC 86(2):412-431

53. Van Haelst AG, Zhao Q, Van der Wielen FWM, Grovers HAJ, De Voogt $P$ (1996) Determination of bioconcentration factors of eight tetrachlorobenzyltoluenes in zebra mussel Dreissena polymorpha. Ecotox Environ Saf 34(1):35-142

54. Lang P-Z, Wang Y, Chen D-B, Wang N, Zhao X-M, Ding Y-Z (1997) Bioconcentration, elimination and metabolism of 2,4-dinitrotoluene in carps (Cyprinus carpio L.). Chemosphere 35(8):1799-1815

55. Wu WZ, Schramm K-W, Xu Y, Kettrup A (2001) Accumulation and partitioning of polychlorinated dibenzo-p-dioxins and dibenzonfurans (PCDD/F) in the muscle and liver of fish. Chemosphere 43(4-7):633-641

56. Webster L, Russell M, Phillips L, Mclntosh A, Walsham P, Packer G, Dalgarno E, McKenzie M, Moffat C (2007) Measurement of organic contaminants and biological effects in Scottish waters between 1999 and 2005. J Environ Monit 9(6):616-629

57. Lu Y, Wang Z (2002) Bioconcentration of trace organochlorine pesticides by the rainbow trout. J Environ Sci Health A 37(4):529-539

58. Zhao X, Zheng M, Liang L, Zhang Q, Wang Y, Jiang G (2005) Assessment of PCBs and PCDD/Fs along the Chinese Bohai Sea coastline using molluscs as bioindicators. Arch Environ Contam Toxicol 49(2):178-185
59. Oliver BG, Niimi AJ (1983) Bioconcentration of chlorobenzenes from water by rainbow trout: correlations with partition coefficients and environmental residues. Environ Sci Technol 17:287-291

60. Zhou R, Zhu L, Chen Y, Kong Q (2008) Concentrations and characteristics of organochlorine pesticides in aquatic biota from Qiantang River in China. Environ Pollut 151(1):190-199

61. Galassi S, Calamari D (1983) Toxicokinetics of 1,2,3 and 1,2,4 trichlorbenzenes in early life stages of Salmo gairdneri. Chemosphere 12(11/12):1599-1603

62. Ferreira M, Antunes $P$, Costa J, Amado J, Gil O, Pousão-Ferreira P, Vale C, Reis-Henriques MA (2008) Organochlorine bioaccumulation and biomarkers levels in culture and wild white seabream (Diplodus sargus). Chemosphere 73(10):1669-1674

63. Guo L, Qui Y, Zhang G, Zheng GJ, Lam PKS, Li X (2008) Levels and bioaccumulation of organochlorine pesticides (OCPS) and polybrominated diphenyl ethers (PBDEs) in fishes from the Pearl River estuary and Daya Bay. South China Environ Pollut 152(3):604-611

64. Balampanis DE, Coulon F, Simms N, Longhurst P, Pollard SJT, Fenech C Villa R (2017) An assessment of different extraction and quantification methods of penta- and hexa-chlorobenzene from SRF fly-ash. Anal Chem Res 12:28-33

65. Twisselmann HAT (1923) Chem-Ztg 47:506; D.R.P. 519371 (1931)

66. Noke A, Christiansen T, Klöck G (2013) Soxhlet or Twisselmann, an evidential report-comparison of techniques for the extraction of lipid from food samples. Filtr Sep 33:32-33

67. Hui LL, Hedley AJ, Kypke K, Cowling BJ, Nelson EAS, Wong TW, van Leeuwen FXR, Malisch R (2008) DDT levels in human milk in Hong Kong, 2001-02. Chemosphere 73(1):50-55

68. Weichbrodt M, Vetter W, Luckas B (2000) Microwave-assisted extraction and accelerated solvent extraction with ethyl acetate-cyclohexane before determination of organochlorines in fish tissue by gas chromatography with electron-capture detection. J AOAC Int 83(6):1334-1343

69. Richter BE, Jones BA, Ezzell JL, Porter NL, Avdalovic N, Pohl C (1996) Accelerated solvent extraction: a technique for sample preparation. Anal Chem 68(6):1033-1039

70. Fisk AT, Stern GA, Hobson KA, Strachan WJ, Loewen MD, Norstrom RJ (2001) Persistent organic pollutants (POPs) in a small, herbivorous, arctic marine zooplankton (Calanus hyperboreus): trends from April to July and the influence of lipids and trophic transfer. Mar Pollut Bull 43(1-6):93-101

71. Balmer ME, Buser H-R, Müller MD, Poiger T (2005) Occurrence of some organic UV filters in wastewater, in surface waters, and in fish from Swiss lakes. Environ Sc Technol 39:935-962

72. Chu S, Metcalf CD (2007) Analysis of paroxetine, fluoxetine and norfluoxetine in fish tissues using pressurized liquid extraction, mixed mode solid phase extraction cleanup and liquid chromatographytandem mass spectrometry. J Chromatogr A 1163(1-2):112-118

73. Giergielewicz-Możajska H, Dąbrowski Ł, Namieśnik J (2001) Accelerated Solvent Extraction (ASE) in the analysis of environmental solid samples - some aspects of theory and practice. Crit Rev Anal Chem 31(3):149-165. https://doi.org/10.1080/20014091076712

74. Dodds ED, McCoy MR, Geldenhuys A, Lorrie DR, Kennish JM (2004) Microscale recovery of total lipids from fish tissue by accelerated solvent extraction. J Am Oil Chem Soc 81:835. https://doi.org/10.1007/ s11746-004-0988-2

75. Schäfer K (1998) Accelerated solvent extraction of lipids for determining the fatty acid composition of biological material. Anal Chim Acta 358:69-77

76. Toschi TG, Bendini A, Ricci A, Lercker G (2003) Pressurized solvent extraction of total lipids in poultry meat. Food Chem 83:551-555

77. Zhuang W, McKague B, Reeve D, Carrey J (2004) A comparative evaluation of accelerated solvent extraction and polytron extraction for quantification of lipids and extractable organochlorine in fish. Chemosphere 54:467-480

78. Boselli E, Velazco V, Caboni MF, Lercker G (2001) Pressurized liquid extraction of lipids for the determination of oxysterols in egg-containing food. J Chromatogr A 917:239-244

79. Richardson RK (2001) Determination of fat in dairy products using pressurized solvent extraction. J Assoc Off Anal Chem Int 84:1522-1533

80. ISO 14156/IDF 172:2001 Milk and milk products-extraction methods for lipids and liposoluble compound. International Standard 
Organisation and Brussels, Genova; International Dairy Federation, Belgium

81. Kotterer R, Münch S (1985) Untersuchungsverfahren für das milchwirtschaftliche Laboratorium. 7. Auflage, Volkswirtschaftlicher Verlag München, Verlag Th. Mann Gelsenkirchen-Buer, Arbeitsgemeinschaft für das milchwirtschaftliche Fachbuch, p. 13-25.

82. Pourmortazavi SM, Saghafi Z, Ehsani A, Yousefi M (2018) Application of supercritical fluids in cholesterol extraction from foodstuffs: a review. J Food Sci Technol 55(8):2813-2823

83. Sapkale GN, Patil SM, Surwase US, Bhatbhage PK (2010) Supercritical fluid extraction-a review. Int J Chem Sci 8(2):729-743

84. Tanaka Y, Sakaki I, Ohkubo T (2004) Extraction of phospholipids from salmon roe with supercritical carbon dioxide and an entrainer. J Oleo Sci 53:417-424

85. Yamada T, Nagasawa Y, Taguchi K, Fukusaki E, Bamba T (2015) Polar lipid profiling by supercritical fluid chromatography/mass spectrometry method. In: Ahmad MU, Xu X (eds) Polar lipids-biology, chemistry, and technology. Elsevier, New York, pp 439-462

86. Hardardottir I, Kinsella JE (2006) Extraction of lipid and cholesterol from fish muscle with supercritical fluids. J Food Sci 53(6):1656-1658. https:// doi.org/10.1111/j.1365-2621.1988.tb07808.x

87. Sánchez-Camargo AP, Martinez-Correa HA, Paviani LC, Cabral FA (2011) Supercritical $\mathrm{CO}_{2}$ extraction of lipids and astaxanthin from Brazilian redspotted shrimp waste (Farfantepenaeus paulensis). J Supercrit Fluid 56(2):164-173. https://doi.org/10.1016/j.supflu.2010.12.009

88. Snyder JM, King JW, Rowe LD, Woerner JA (1993) Supercritical fluid extraction of poultry tissues containing incurred pesticide residues. J AOAC International 76(4):888-892

89. Commission Recommendation 2014/663/EU of 11 September 2014 amending the Annex to Recommendation 2013/711/EU on the reduction of the presence of dioxins, furans and PCBs in feed and food. OJ L 272, 13.9.2014, pp 17-18

90. Commission Regulation (EU) No 1259/2011 of 2 December 2011 amending Regulation (EC) No 1881/2006 as regards maximum levels for dioxins, dioxin-like PCBs and non dioxin-like PCBs in foodstuffs. OJ L 320, 3.12.2011, pp 18-23

91. Commission Regulation (EU) No 1067/2013 of 30 October 2013 amending Regulation (EC) No. 1881/2006 as regards maximum levels of the contaminants dioxins, dioxin-like PCBs and non-dioxin-like PCBs in liver of terrestrial animals. OJ L 289, 31.10.2013, pp 56-57

92. Regulation (EC) No $396 / 2005$ of the European Parliament and of the Council of 23 February 2005 on maximum residue levels of pesticides in or on food and feed of plant and animal origin and amending Council Directive 91/414/EECText with EEA relevance. OJ L 70, 16.3.2005, pp $1-16$

93. Randall RC, Lee H II, Ozretich RJ, Lake JL, Pruell RJ (1991) Evaluation of selected methods for normalizing pollutant bioaccumulation. Environ Toxicol Chem 10:1431-1436

94. Kotz A, Malisch R, Wahl K, Haedrich J (2012) Comparison of extraction methods for determination of PCDD/Fs, PCBs and lipids in food of animal origin and consequences for control of maximum levels. Organohalogen Compd 74:160-163

95. Federal Institute for Risk Assessment (BfR): BfR opinion No 014/2014, 11 (2014) New EU maximum levels for dioxins, dioxin-like PCBs and nondioxin-like PCBs in livers of terrestrial animals and in sheep liver

96. Scientific Committee on Food (SCF) (2000) Opinion of the SCF on the Risk Assessment of Dioxins and Dioxin-like PCBs in Food, adopted on 22 November 2000. European Commission, Brussels

97. SCF (Scientific Committee on Food) (2001) Opinion of the SCF on the Risk Assessment of Dioxins and Dioxin-like PCBs in Food, update based on new scientific information available since the adoption of the SCF opinion on 22 November 2000, adopted on 30 May 2001. European Commission, Brussels

98. European Comission (2000) Report on the Task 3.2.5. of the Scientific Cooperation; Assessment of dietary intake of dioxins and related PCBs by the population of EU Member States

99. Larrson P, Backe C, Bremle G, Eklöv A, Okla L (1996) Persistent pollutants in a salmon population (Salmo salar) of the southern Baltic sea. Can J Fish Aquat Sci 53:62-69

100. Regulation (EC) No 882/2004 of the European Parliament and of the Council of 29 April 2004 on official controls performed to ensure the verification of compliance with feed and food law, animal health and animal welfare rules. OJ L 165, 30.4.2004, pp 1-141

101. International Union of Pure and Applied Chemistry (IUPAC) (2006) International harmonized protocol for the proficiency testing of analytical chemistry laboratories. IUPAC Technical Report Pure Appl Chem 78(1):145-196

102. Huber PJ (1981) Robust statistics. Wiley, New York

103. Commission Recommendation 2006/88/EC of 6 February 2006 on the reduction of the presence of dioxins, furans and PCBs in feedingstuffs and foodstuffs. OJ L 42, 24.02.2006, pp 26-28

104. Haedrich J, Stumpf C, Denison MS (2018) Bioanalytical screening for dioxins and PCBs in EU-regulated foods: new analytical criteria adopted by the European Union in Commission Regulation (EU) 2017/644. Part 1: Introduction. Deut Lebensm Rundsch 3:99-108

105. Haedrich J, Stumpf C, Denison MS (2018) Bioanalytical Screening for Dioxins and PCBs in EU-regulated Foods: New Analytical Criteria adopted by the European Union in Commission Regulation (EU) 2017/644. Part 2: sample analysis criteria and the nature of bioanalytical results. Deut Lebensm Rundsch 4:167-175

106. Haedrich J, Stumpf C, Denison MS (2018) Bioanalytical Screening for Dioxins and PCBs in EU-regulated Foods: New Analytical Criteria adopted by the European Union in Commission Regulation (EU) 2017/644. Part 3: assay criteria, validation and quality control, reporting of results. Implementation Deut Lebensm Rundsch 5:215-228

107. Haedrich J, Stumpf C, Denison MS (2018) Ah-receptor based bioassay screening for PCDD/Fs and dioxin-like PCBs in human milk samples from a WHO/UNEP global survey on halogenated POPs. Deut Lebensm Rundsch 9:389-397

108. Swiss Food Composition Database (V6.0). Federal Food Safety and Veterinary Office FSVO, Last modification: 27.02.2019. https://www.naehr wertdaten.ch/en/. Accessed 15 Mar 2020

109. Brown DJ, Chu M, Van Overmeire I, Chu A, Clark GC (2001) Determination of REP values for the CALUX bioassay and comparison to the WHO TEF values. Organohalogen Compd 53:211-214

110. Carbonnelle S, Loco J, Overmeire I, Windal I, Van Wouwe N, Leeuwen S, Goeyens L (2004) Importance of REP values when comparing the CALUX bioassay results with chemoanalyses results: example with spiked vegetable oils. Talanta 63(5):1255-1259

111. Scippo ML, Eppe G, De Pauw E, Maghuin-Rogister G (2004) DR-CALUX ${ }^{\circledR}$ screening of food samples: evaluation of the quantitative approach to measure dioxin, furans and dioxin-like PCBs. Talanta 63(5):1193-1202

112. Denison MS, Zhao B, Baston DS, Clark GC, Murata H, Han D (2004) Recombinant cell bioassay systems for the detection and relative quantitation of halogenated dioxins and related chemicals. Talanta 63:1123-1133

113. Denison MS, Soshilov AA, He G, DeGroot DE, Zhao B (2011) Exactly the same but different: promiscuity and diversity in the molecular mechanisms of action of the aryl hydrocarbon (dioxin) receptor. Toxicol Sci 124:1-22

114. Garrison PM, Tullis K, Aarts JM, Brouwer A, Giesy JP, Denison MS (1996) Species-specific recombinant cell lines as bioassay systems for the detection of 2,3,7,8-tetrachlorodibenzo-p-dioxin-like chemicals. Fundam Appl Toxicol 30(2):194-203

115. Murk AJ, Legler J, Denison MS, Giesy JP, van de Guchte C, Brouwer A (1996) Chemical-Activated Luciferase Expression (CALUX): a novel in vitro bioassay for ah receptor active compounds in sediments and pore water. Fundam Appl Toxicol 33(1):149-160

116. Denison MS, Nagy SR (2003) Activation of the aryl hydrocarbon receptor by structurally diverse exogenous and endogenous chemicals. Annu Rev Pharmacol Toxicol 43:309-334

117. Han DH, Nagy SR, Denison MS (2004) Comparison of recombinant cell bioassays for the detection of Ah receptor agonists. BioFactors 20:11-22

118. Brennan JC, He G, Tsutsumi T, Zhao J, Wirth E, Fulton MH, Denison MS (2015) Development of species-specific Ah receptor-responsive third generation CALUX cell lines with increased sensitivity and responsiveness. Environ Sci Tech 49:11903-11912

119. Zhao B, Baston DS, Khan E, Sorrentino C, Denison MS (2010) Enhancing the response of CALUX and CAFLUX cell bioassays for quantitative detection of dioxin-like compounds. Sci China Chem (Science in China Series B) 53:1010-1016 
120. De Lean AP, Munson J, Rodbard D (1978) Simultaneous analysis of families of sigmoidal curves: application to bioassay, radioligand assay, and physiological dose-response curves. Am J Physiol 235:E97-E102

121. International Organisation for Standardisation (2008) ISO/IEC Guide 98-3:2008: uncertainty of measurement - part 3: guide to the expression of uncertainty in measurement. ISO, Geneva

122. IUPAC (1997) Compendium of Chemical Terminology, 2nd ed. (the "Gold Book"). Compiled by A. D. McNaught and A. Wilkinson. Blackwell Scientific Publications, Oxford. Online version (2019-) created by S. J. Chalk. ISBN 0-9678550-9-8. https://doi.org/10.1351/goldbook.U06553

123. BIPM, IEC, IFCC, ILAC, IUPAC, IUPAP, ISO, OIML (2008/2012) The international vocabulary of metrology - basic and general concepts and associated terms (VIM), 3rd edn. JCGM at https://www.bipm.org/vim

124. De Bievre P (2013) "Analyte" is frequently used as synonym for "measurand": is that correct? Accred Qual Assur 18(71):72. https://doi. org/10.1007/s00769-012-0953-8

125. IUPAC (1997) Compendium of Chemical Terminology, 2nd ed. (the "Gold Book"). Compiled by A. D. McNaught and A. Wilkinson. Blackwell Scientific Publications, Oxford. Online version (2019-) created by S. J. Chalk. ISBN 0-9678550-9-8. https://doi.org/10.1351/goldbook.M03796

126. United Nations Environment Programme (UNEP) (2019) Guidance on the global monitoring plan for persistent organic pollutants, 3rd edn. Secretariat of the Stockholm Convention on Persistent Organic Pollutants, Geneva

127. Brennen CE (1995) Cavitation and Bubble Dynamics. Oxford University Press. ISBN: 978-1-10-764476-2

128. Boye JI (2015) Nutraceutical and Functional Food Processing Technology. Wiley-Blackwell, Hoboken

129. Stopar D. Hydrodynamic Cavitation. https://davidstopar.wixsite.com/ home/hydrodynamic-cavitation. Accessed 15 Mar 2020

130. Brennen CE (2015) Cavitation in medicine. Interface Focus 5(5):1-11

131. Watson DW (2017) Tips for troubleshooting liquid-liquid extractions. LCGC North Am 35(12):886

132. Erich S, Probst A, Lais A, Hädrich J, Monakhovaz Y, Annweiler E (2014) Methoden zur Echtheitsüberprüfung von Bio-Milch. Lebensmittelchemie 68:117-164

133. Anton M, Martinet $V$, Dalgalarrondo M, Beaumal V, David-Briand E, Rabesona H (2003) Chemical and structural characterisation of low-density lipoproteins purified from hen egg yolk. Food Chem 83(2):175-183
134. Greene CM Waters D, Clark RM, Contois JH, Fernandez ML (2006) Plasma LDL and HDL characteristics and carotenoid content are positively influenced by egg consumption in an elderly population. Nutr Metab (Lond) 3:6

135. Walstra P (1995) Physical chemistry of milk fat globules. In: Fox PF (ed). Advanced Dairy Chemistry, Vol 2 Lipids, 2 edn. Chapman \& Hall, London, pp. 131-178.

136. Wells DE (2000) QUASIMEME-QUASH. Quality Assurance of Information for Marine Environmental Monitoring in Europe-Quality Assurance of Sampling and Sample Handling. J Environ Monit 2(5):69N-70N

137. Huber PJ (2009) Robust statistics. John Wiley \& Sons, New York. Republished in paperback 2004, 2nd edn. Wiley, New York

138. Hahn ME (2002) Biomarkers and bioassay for detecting dioxin-like compounds in the marine environment. Sci Total Environ 289:49-69

139. Whyte JJ, Schmitt CJ, Tillitt DE (2004) The H4IIE cell bioassay as an indicator of dioxin-like chemicals in wildlife and the environment. Crit Rev Toxicol 34(1):1-83

140. Eichbaum K, Brinkmann M, Buchinger S, Reifferscheid G, Hecker M, Giesy JP, Engwall M, van Bavel B, Hollert H (2014) In vitro bioassays for detecting dioxin-like activity-application potentials and limits of detection, a review. Sci Total Environ 487:37-48

141. Eichbaum K, Brinkmann M, Nuesser L, Gembé C, Ohlig M, Buchinger S, Reifferscheid G, Hecker M, Giesy JP, Hollert H (2018) In vitro tools for the toxicological evaluation of sediments and dredged materials: intra- and inter-laboratory comparisons of chemical and bioanalytical methods. Environ Sci Pollut Res Int 25(5):4037-4050

142. Schiwy A, Brinkmann M, Thiem I, Guder G, Winkens K, Eichbaum K, Nüßer L, Thalmann B, Buchinger S, Reifferscheid G, Seiler TB, Thoms B, Hollert H (2015) Determination of the CYP1A-inducing potential of single substances, mixtures and extracts of samples in the micro-EROD assay with H4IIE cells. Nat Protoc 10(11):1728-1741

\section{Publisher's Note}

Springer Nature remains neutral with regard to jurisdictional claims in published maps and institutional affiliations.

\section{Submit your manuscript to a SpringerOpen ${ }^{\circ}$ journal and benefit from:}

- Convenient online submission

- Rigorous peer review

- Open access: articles freely available online

- High visibility within the field

Retaining the copyright to your article

Submit your next manuscript at springeropen.com 